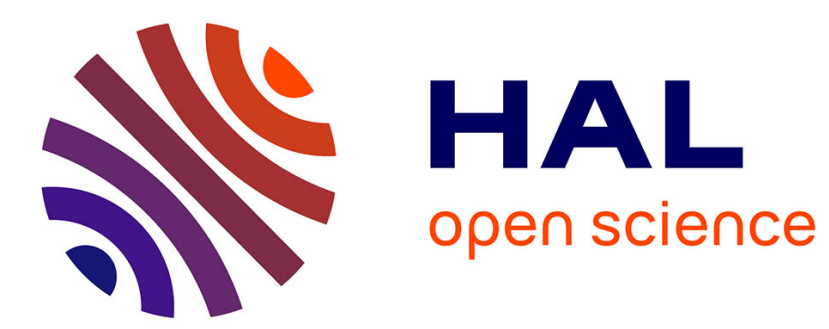

\title{
Envenimations marines vues en consultation post-voyage à la Pitié Salpêtrière entre 2008 et 2013
}

Aurélia Henn

\section{To cite this version:}

Aurélia Henn. Envenimations marines vues en consultation post-voyage à la Pitié Salpêtrière entre 2008 et 2013. Médecine humaine et pathologie. 2014. dumas-01115408

\section{HAL Id: dumas-01115408 https://dumas.ccsd.cnrs.fr/dumas-01115408}

Submitted on 11 Feb 2015

HAL is a multi-disciplinary open access archive for the deposit and dissemination of scientific research documents, whether they are published or not. The documents may come from teaching and research institutions in France or abroad, or from public or private research centers.
L'archive ouverte pluridisciplinaire HAL, est destinée au dépôt et à la diffusion de documents scientifiques de niveau recherche, publiés ou non, émanant des établissements d'enseignement et de recherche français ou étrangers, des laboratoires publics ou privés.

\section{(1) (1) $\$$}

Distributed under a Creative Commons Attribution - NonCommercial - NoDerivatives| 4.0 


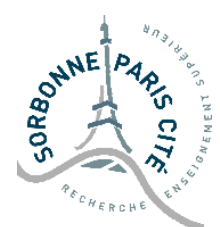

\section{AVERTISSEMENT}

Cette thèse d'exercice est le fruit d'un travail approuvé par le jury de soutenance et réalisé dans le but d'obtenir le diplôme d'Etat de docteur en médecine. Ce document est mis à disposition de l'ensemble de la communauté universitaire élargie.

Il est soumis à la propriété intellectuelle de l'auteur. Ceci implique une obligation de citation et de référencement lors de l'utilisation de ce document.

D’autre part, toute contrefaçon, plagiat, reproduction illicite encourt toute poursuite pénale.

Code de la Propriété Intellectuelle. Articles L 122.4

Code de la Propriété Intellectuelle. Articles L 335.2-L 335.10 


\section{UNIVERSITÉ PARIS DESCARTES \\ Faculté de Médecine PARIS DESCARTES}

Année 2014

$\mathrm{N}^{\circ}$

\section{THÈSE \\ POUR LE DIPLÔME D'ÉTAT \\ DE DOCTEUR EN MÉDECINE}

Envenimations marines vues en consultation postvoyage à la Pitié Salpêtrière entre 2008 et 2013.

Présentée et soutenue publiquement

le 6 octobre 2014

Par

HENN, Aurelia

Née le 6 juillet 1984 à Paris 14ème

Dirigée par Mme le Docteur Monsel, Gentiane

Jury :

M. Le Professeur CAUMES Eric, PU-PH

Président

M. Le Professeur DESCAMPS Vincent, PU-PH

M. Le Docteur Petit Antoine, PH

(c) $9 . \begin{aligned} & \text { Except where otherwise noted, this work is licensed under } \\ & \text { http://creativecommons.org/licenses/by-nc-nd/3.0/ }\end{aligned}$ 


\section{Remerciements :}

- Au Pr Eric Caumes, pour m'avoir permis de faire cette thèse à ses côtés, en alliant la dermatologie, les maladies infectieuses, les voyages, et la plongée. Merci de m’avoir accompagnée tout au long de cette thèse comme de mes études, et pour votre enseignement de la dermatologie infectieuse. Votre confiance m'honore.

- Au Dr Gentiane Monsel, pour avoir gentiment accepté d'être ma directrice de thèse.

- Au Pr Jean-Daniel Lelièvre, pour avoir accepté de faire parti de mon jury de thèse, et de m'accorder votre confiance pour travailler prochainement à vos côtés.

- Au Pr Vincent Descamps, pour me faire l'honneur de juger ma thèse, pour votre enseignement de la dermatologie et votre gentillesse, et pour avoir démontré que l'on peut allier médecine et sport, tout les deux à haut niveau.

- Au Dr Antoine Petit, pour me faire l'honneur de participer à ce jury, pour votre amour de la dermatologie et des patients que vous avez su me transmettre.

- Au Dr Alice Pérignon, qui m'a aidée pour identifier les cas, sortir les dossiers, retrouver les photos... Sans ton aide précieuse ce travail n'aurait pu voir le jour. Je te remercie chaleureusement.

- Aux équipes de maladies infectieuses et de bactériologie de Saint Antoine, qui m'accueillez moi et mon classeur pour mon dernier semestre, pour vos réponses à toutes mes questions. En particulier aux Dr Laure Surgers, Jean-Luc Meynard, Jérôme Pacanowski, Valérie Lalande et Karine Lacombe ; votre amitié m’honore.

- A l'équipe de maladies infectieuses du CHU de Pointe à Pitre, et tout particulièrement au Pr Bruno Hoen et au Dr Elodie Curlier. Votre rigueur, votre savoir, votre gentillesse, et votre confiance m'ont beaucoup apporté et ont été un exemple pour moi. Vous avez rendu mon séjour guadeloupéen encore plus beau. Même si cela n'aura finalement été que pour 6 mois, ils resteront pour moi inoubliables.

Merci aussi aux Dr Babe Fernandes, Stéphanie Balavoine, Kinda Schepers et Rachida Ouissa pour votre enseignement pendant ce semestre. Merci à mes co-internes antillais, Geoffroy, Thibault, Elodie et Léna pour tous ces bons moments passés ensemble, pour l'entraide en cas de panne de voiture ou de grève d'essence... 
- A l'équipe de dermatologie de Saint Louis, en particulier aux Dr Antoine Petit, Michel Rybojad, Jean-David Bouaziz, et Florence Cordoliani pour votre enseignement de grande qualité. Merci au Dr Béatrice Flageul pour m'avoir transmis votre savoir et votre intérêt pour la lèpre.

- A l'équipe de maladies infectieuses de la Pitié Salpêtrière, au Pr Caumes pour avoir partagé son savoir, et tout particulièrement merci aux Dr Benoit Henry, Loïc Epelboin et Guillaume Mellon pour votre encadrement, votre savoir, vos encouragements et votre amitié.

Merci à mes co-internes de ce stage, pour votre entraide, votre soutien et votre amitié, en particulier Anne-Line et Guillaume.

- Aux services de dermatologie de l'hôpital Bichat et Cochin pour m'avoir permis d'apprendre la dermatologie à vos côtés, notamment les Pr Crickx et Dupin. Merci également aux Dr Charlotte Fite, Julie Di Lucca et Eve Maubec.

Merci à mes co-internes et en particulier à Antoine Badaoui pour m'avoir appris à dire non et à sortir tôt.

- Aux services de néphrologie du Pr Vrtovsnik et de médecine interne du Pr Rouveix pour m'avoir accompagnée dans les débuts de l'internat.

Merci à Geisa pour son amitié, et ses cours de portugais ici ou au Brésil.

- Merci à Mathilde et Solène pour votre fidèle amitié dès le début de ces longues études, où que nous ayons pu être dans le monde. Votre amitié m'est précieuse.

Merci à Manie, pour ton amitié et notamment pour ton soutien durant l'écriture de cette thèse.

Merci à Hai Tien, pour le début commun de notre voyage qui a été si important pour moi.

Merci aussi à Xavier, Jota B, Lucile, Marie-Laure, Jeanne, et Cécile.

Merci à Kalia et à Sylvie pour votre fidèle amitié depuis tant d'années, je n'ose même plus compter... 
- A mes parents, merci pour votre soutien constant dans les études mais surtout dans le reste, merci pour la confiance que vous m'avez toujours accordée, et de m'avoir permis de voyager dès mon plus jeune âge. Merci de m'avoir accueilli en pension complète à Vallorcine et m'avoir ainsi permis d'enfin écrire cette thèse.

- A Alexandra, ma petite sœur adorée...

- A mon frère Edouard, ma belle-sœur Alexandra et ma nièce Elena.

- A mes oncles, tantes, cousins et cousines.

- A Pascal, pour ton amour, et pour rendre ma vie plus belle. 


\section{Table des matières :}

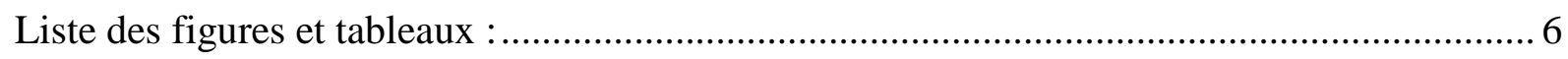

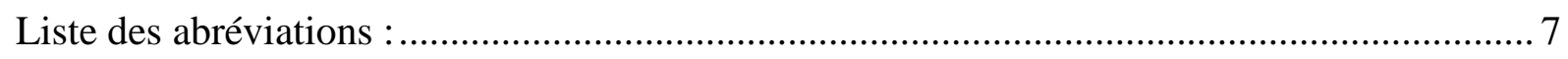

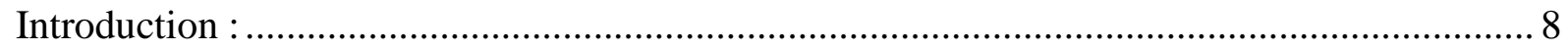

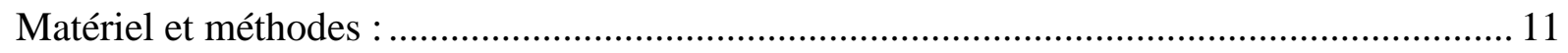

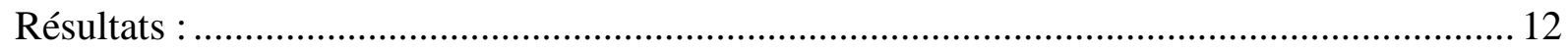

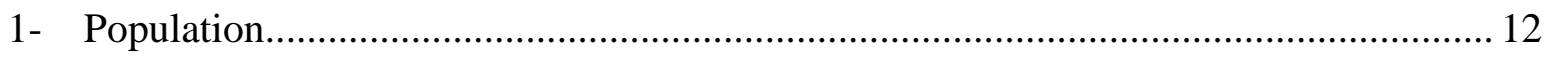

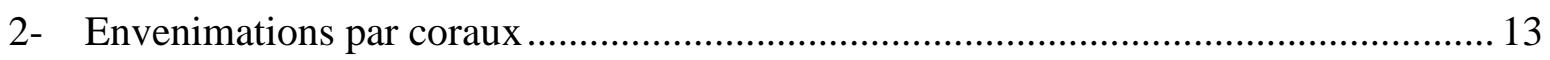

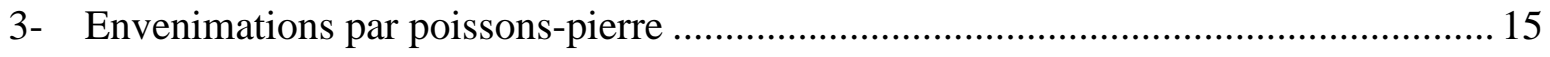

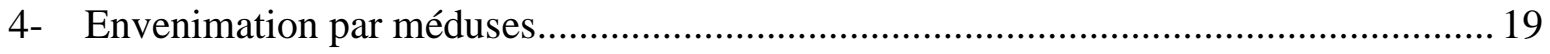

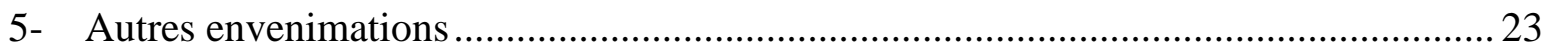

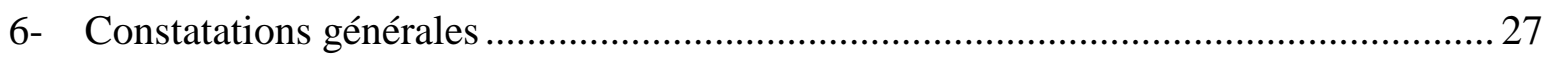

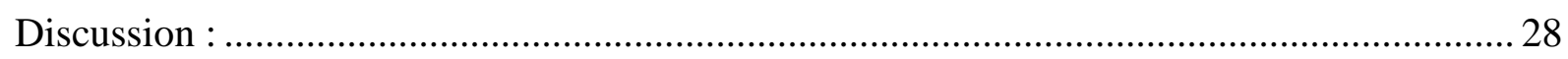

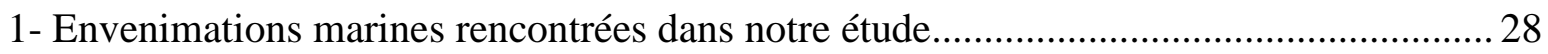

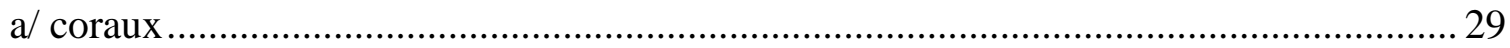

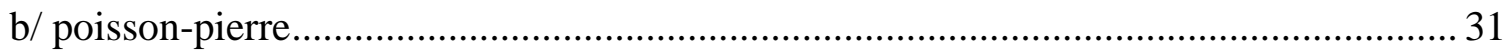

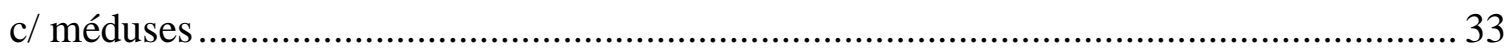

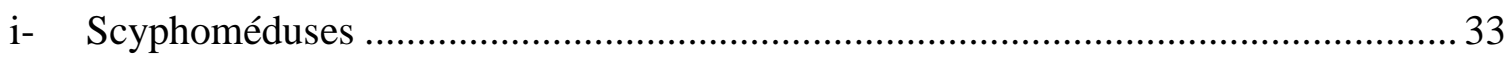

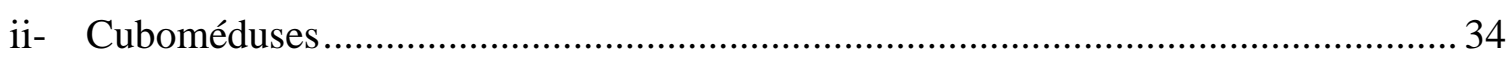

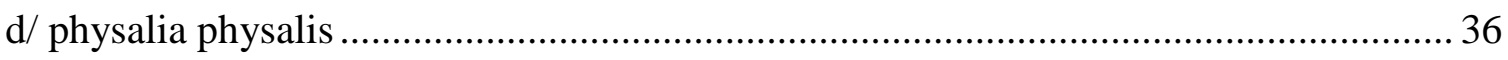

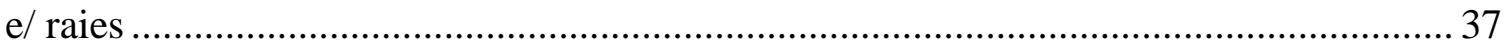

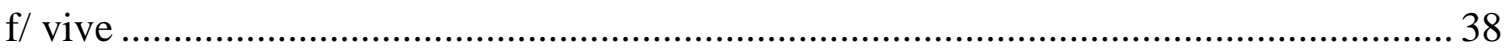

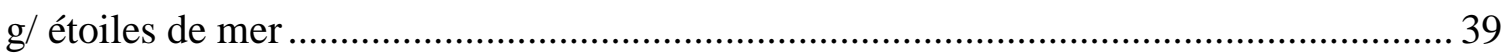

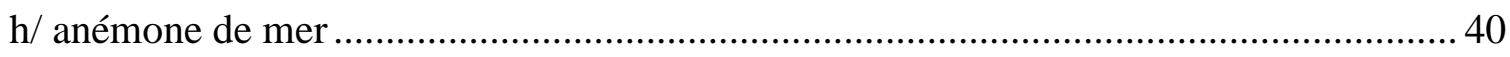

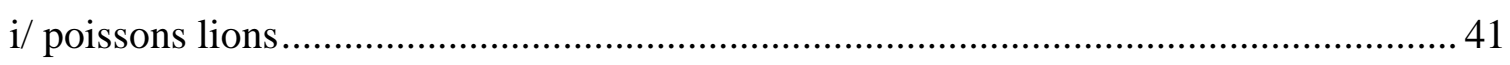

2- Complications bactériennes des envenimations marines ............................................ 42

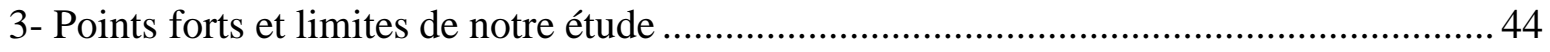

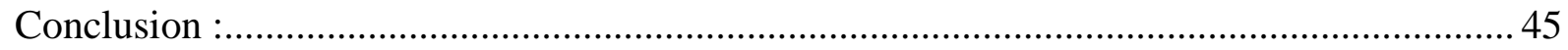

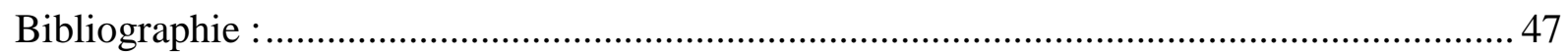

Annexe $1:$ message d'information du gouvernement du Northern Territory (Australie) ........ 51 


\section{Liste des figures et tableaux :}

Figure 1 : causes de décès parmi les voyageurs à l'étranger. Comparaison entre des études de

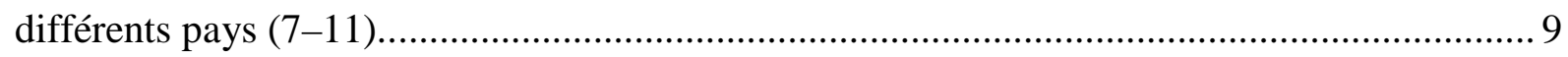

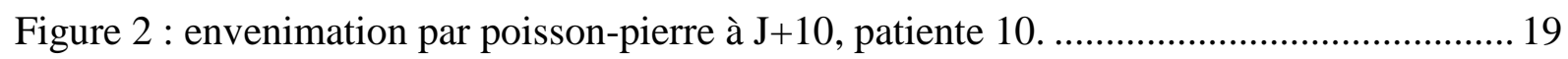

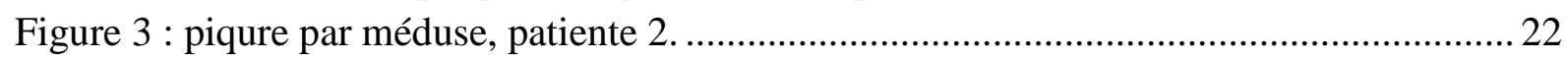

Figure 4 : J7 d'une envenimation marine par cuboméduse, patient 7, dos et bras.................. 22

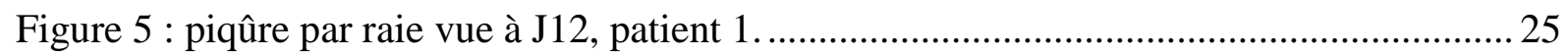

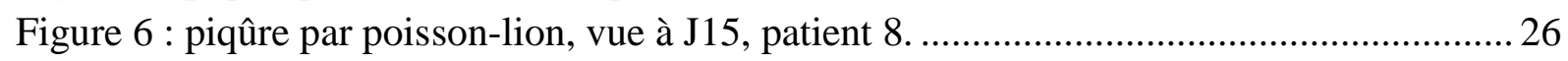

Figure 7: envenimation par anémone de mer, patiente 7. A 30min, J5 puis J16................... 26

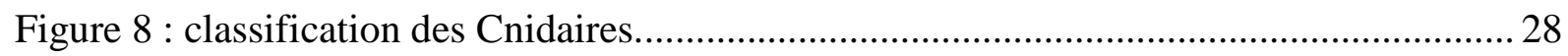

Figure 9 : réaction d'hypersensibilité retardée de contact mimant les marques du corail

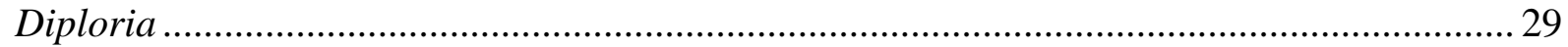

Figure 10 : Millepora dichotoma, ou corail de feu. Egypte ................................................ 30

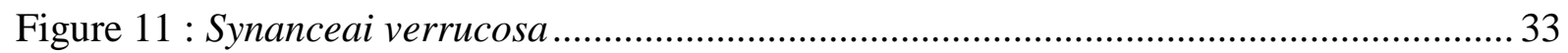

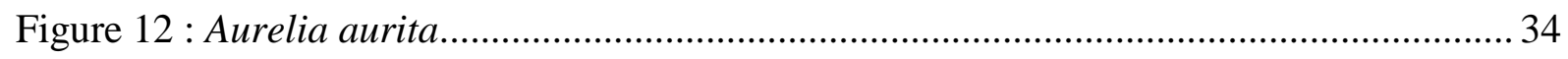

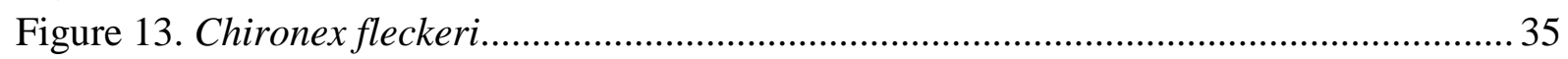

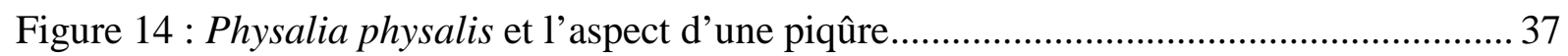

Figure 15 : Taeniura lymma, ou raie pastenague à pois bleus ................................................. 38

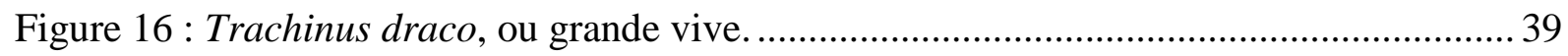

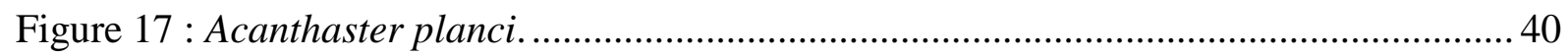

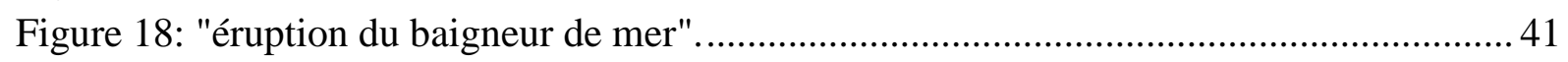

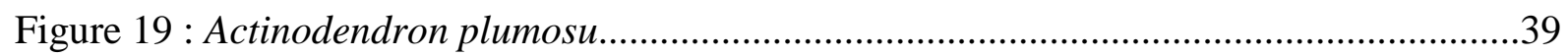

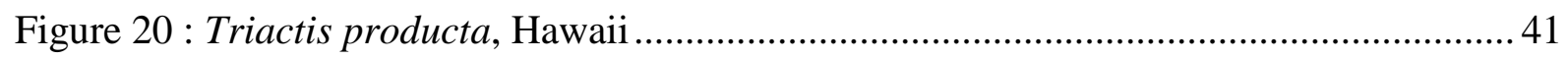

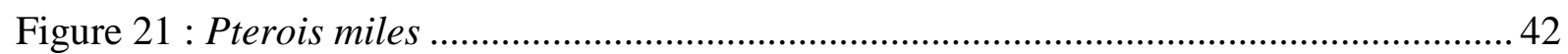

Figure 22 : distribution mondiale des cas rapportés d'envenimation par cuboméduses........43

Tableau 1 : destinations de voyage des patients consultant pour envenimations marines ....... 13

Tableau 2 : caractéristiques des patients ayant eu une envenimation par coraux .................... 15

Tableau 3 : caractéristiques des patients piqués par poisson-pierre ..................................... 17

Tableau 4 : évolution des patients piqués par poisson-pierre.............................................. 18

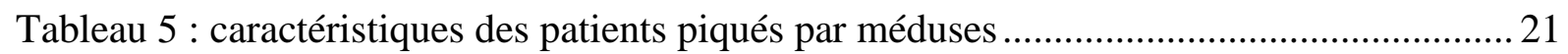

Tableau 6 : caractéristiques des patients ayant d'autres causes d'envenimation marine .......... 25

Tableau 7 : algorithme de prise en charge en cas d'envenimation par poisson-pierre.............. 32 


\section{Liste des abréviations :}

ACR : arrêt cardio-respiratoire

AG : anesthésie générale

AINS : Anti Inflammatoire Non Stéroïdien

ALAT : ALanine Amino-Transférase

ASAT : ASpartate Amino-Transférase

C3G : céphalosporines de $3^{\mathrm{e}}$ génération

CRP : C Reactive Protein

D : Droit(e)

DTP : Diphtérie Tétanos Poliomyélite

DTPc : Diphtérie Tétanos Poliomyélite coqueluche

G : Gauche

HBPM : Héparine de Bas Poids Moléculaire

HSV : Herpès Simplex Virus

$\mathrm{J}:$ jours

NFS : Numération Formule Sanguine

OAP : Edème Aigu Pulmonaire

PCR : Polymerase Chain Reaction

PMT : Palmes Masque Tuba

VHA, VHB, VHC : Virus de l'Hépatite A, B ou C 


\section{Introduction :}

Il est de nos jours de plus en plus facile de voyager, y compris à l'étranger. Le nombre de voyageurs internationaux n'a cessé d'augmenter, avec depuis 2012 plus d'un milliard de touristes internationaux par an. Les destinations choisies sont l'Europe pour $52 \%$ des voyageurs dans le monde, la région Asie-Pacifique pour 23\%, les Amériques pour 15\%, l'Afrique pour 5\%, et le Moyen-Orient pour 5\%.(1) Les pathologies rencontrées dans les zones intertropicales peuvent donc être de plus en plus souvent importées en France.

Les vacances en bord de mer sont souvent prisées, notamment sous les tropiques. Les activités marines se multiplient, comme la baignade, le PMT (palmes masque tuba, ou snorkeling en anglais), la plongée, le surf, le kitesurf... Cependant, les plages paradisiaques peuvent se révéler dangereuses: la mer contient bon nombre d'animaux et de plantes potentiellement venimeux. Les envenimations marines sont devenues un problème majeur en Australie, en particulier à cause des méduses-boites (box-jellyfish en anglais), dont Chironex fleckeri, réputé être l'animal le plus venimeux au monde. On compte 68 morts en Australie à cause des méduses-boites depuis le début des registres en 1883.(2) Pourtant de nombreuses mesures sont prises : panneaux d'informations, baignade déconseillée entre novembre et mai, port de combinaisons intégrales anti-méduses, présence de filets anti-méduses dans l'eau, de vinaigre sur les plages, disponibilité des secours et du sérum anti venin (voir annexe 1).

Compte tenu entre autre du réchauffement climatique, la présence des méduses-boites s'étend. Donnée moins connu du grand public, elles se sont également répandues en Asie du Sud-Est, où il existe chaque année des cas mortels, mais bien moins de mesures de prévention et d'information aux touristes. $(3,4)$ Un décès très récent dû à une envenimation par méduseboite en Thaïlande a cependant été révélé au grand public.(5)

Les poissons-pierre, autre cause d'envenimation marine importante, sont réputés être les poissons les plus venimeux au monde. Ils peuvent provoquer de rares décès, mais surtout des conséquences locales graves à court, moyen, et long terme.

D’une manière générale, les envenimations marines représentent un danger croissant chez les voyageurs, pouvant parfois être mortel. Malgré cela, les voyageurs les craignent rarement avant de partir, mais beaucoup plus les envenimations terrestres: crainte des 
serpents, scorpions, insectes divers... Cependant, les rencontres de ce genre sont beaucoup plus rares chez les touristes.

Behrens et al a comparé les causes de mortalité en voyage d'après différentes études.(6) Les résultats sont donnés ci-dessous :

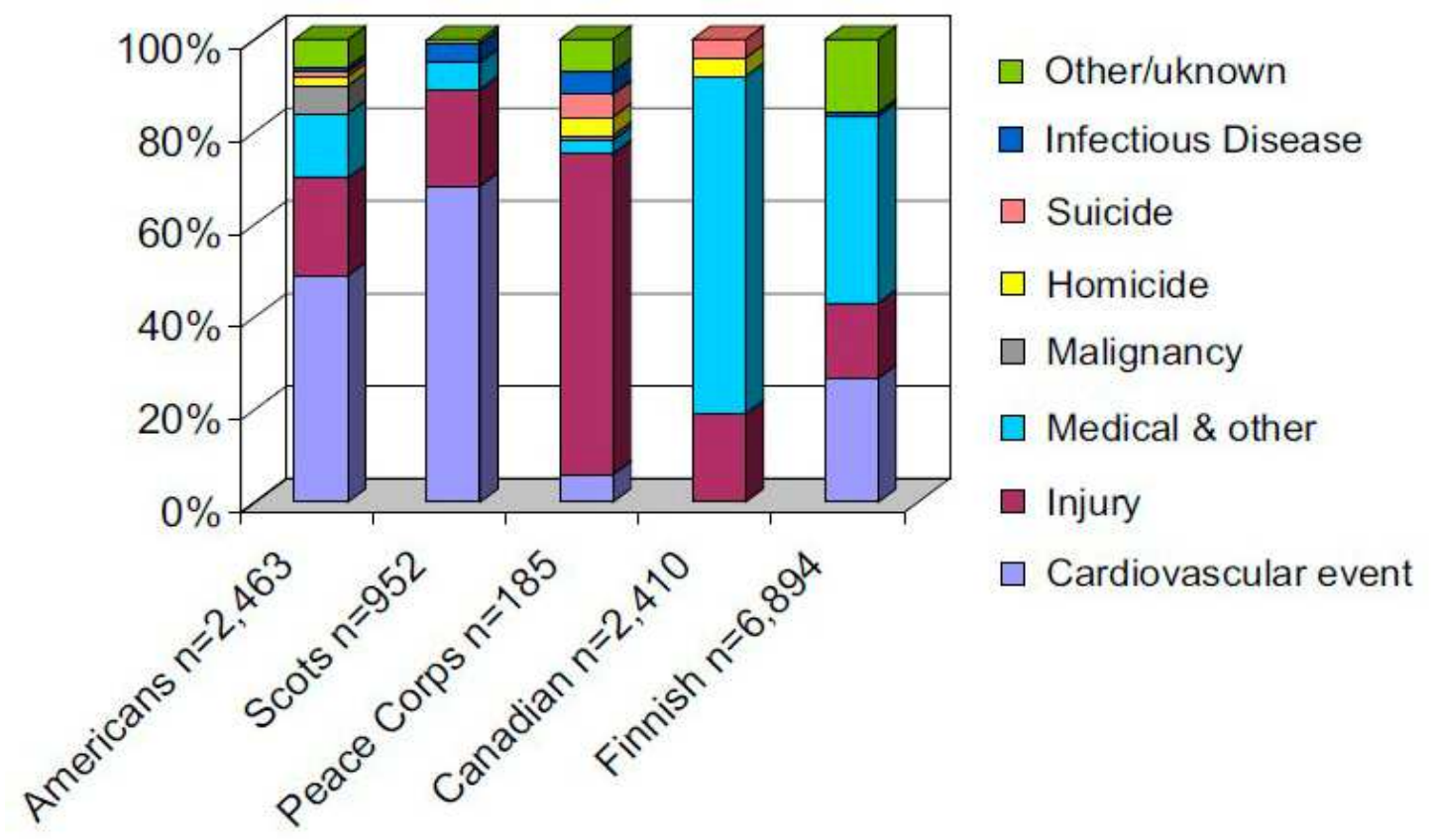

Figure 1 : causes de décès parmi les voyageurs à l'étranger. Comparaison entre des études de différents pays (7-11). Tiré de (6).

On constate que les maladies infectieuses ne représentent à chaque fois qu'un faible pourcentage.

Il existe depuis 1997 un système international de surveillance des pathologies liées aux voyages, appelé GeoSentinel. Il comporte 54 centres de voyages et maladies tropicales, répartis sur les 6 continents. Ce réseau utilise un système standardisé, informatisé, de recueil de données pour chaque consultant.(12) La Pitié Salpêtrière fait partie du réseau GeoSentinel, et propose des consultations médicales sans rendez-vous pour les personnes rentrant de voyage.

Les données GeoSentinel aux Etats-Unis entre septembre 1997 et décembre 2011 pour des pathologies liées au voyage concernent 10032 patients au retour de voyage, soit 13059 diagnostics. Parmi ceux-ci, on retrouve 1596 problèmes dermatologiques, soit $12 \%$. On retrouve 237 cas de piqûre d'insecte ou morsure, qui est la première cause des consultations pour problème dermatologique $(15 \%)$. Les autres causes principales sont des exanthèmes non 
fébriles d'origine inconnue (10\%), les infections fongiques (7\%), la leishmaniose cutanée (6\%), les infections de la peau et des tissus mous (6\%). Les autres 56\% des causes de consultation pour problème dermatologique ne sont pas détaillés dans l'article.(13) La fréquence des consultations pour envenimations marines spécifiquement n'est pas précisée.

Une autre étude munichoise concernant 34162 patients de retour de voyage retrouve des pathologies cutanées chez $12 \%$ des consultants (4 158 patients). Parmi ceux-ci, la première cause est due aux arthropodes pour $22.6 \%$ des patients : piqûres d'insectes $16.8 \%$, ectoparasites $5.6 \%$ (gale, myiases, tiques, tungose). Ensuite viennent les causes bactériennes (21.6\%), les helminthes (10.5\%), les protozoaires $(6.0 \%)$, les virus $(5.7 \%)$, les allergies $(5.4 \%)$, les causes fongiques $(4.0 \%) \ldots$ Les envenimations marines ont concerné 30 voyageurs, soit $0.7 \%$, les envenimations terrestres (morsures) 15 voyageurs $(0.4 \%) .(14)$

Le spectre précis des envenimations marines chez le voyageur est cependant inconnu.

L'objectif de ce travail est de colliger les cas d'envenimations marines vues en consultation post-voyage entre 2008 et 2013 à la Pitié Salpêtrière, d'étudier les données épidémiologiques, de décrire les lésions dermatologiques engendrées par ces envenimations, et d'en préciser la prise en charge. 


\section{Matériel et méthodes :}

Nous avons recherché dans la base de données GeoSentinel de l'hôpital de la Pitié Salpêtrière tous les patients consultant après un voyage pour envenimation marine, entre 2008 et 2013 .

Nous avons ensuite étudié chacun de ces dossiers et colligé les informations suivantes :

- Sur le patient : âge, antécédents médicaux, dates et lieu du voyage.

- Sur l'envenimation marine: date de l'envenimation, cause présumée de l'envenimation, symptômes et traitements immédiats, traitements et évolution secondaires.

- Sur la consultation: date de consultation, délai entre l'envenimation et la consultation, symptômes et constatations cliniques lors de la consultation, traitements et explorations proposés, évolution et traitements ultérieurs le cas échéant.

Le diagnostic de l'espèce animale présumée responsable était basé sur l'interrogatoire du voyageur et la corrélation avec les données épidémiologiques et cliniques.

Les critères d'exclusion étaient un diagnostic d'envenimation marine incertain, ou des données insuffisantes concernant l'envenimation. 


\section{Résultats :}

\section{1- Population}

3315 patients ont été vu en consultation post-voyage à la Pitié Salpêtrière entre 2008 et 2013. Nous avons identifié 43 cas d'envenimations marines à partir des données GeoSentinel.

Nous avons dû exclure 6 patients :

- un patient ayant eu une blessure par corail pour absence de données cliniques,

- un patient piqué par un poisson pierre pour absence de données sur la date et le lieu du voyage

- 4 patients pour absence de cause retrouvée aux symptômes, et absence de certitude d'envenimation marine.

Au total, nous avons retenu 37 patients : 11 cas d'envenimation marine par coraux, 10 cas par poisson pierre, 8 cas par méduses, 2 cas par vives, 2 cas par étoiles de mer, 2 cas par raies, un cas par poisson lion, un cas par anémone de mer.

Les envenimations marines représentent donc $1,1 \%$ des consultations post-voyage.

Le sex ratio est équilibré avec 18 hommes pour 19 femmes. L'âge médian des patients est de 42 ans (extrêmes de 25 à 68 ans). La durée médiane de séjour est de 14 jours (extrêmes de 6 à 62 jours). Le but du voyage était le tourisme dans 100\% des cas.

La destination de voyage a été le plus souvent l'Asie du Sud Est et du Sud, suivie par les îles à l'Est de l'Afrique (Madagascar, Réunion, île Maurice, Rodrigues). Le détail est présenté dans le tableau 1.

\begin{tabular}{lc} 
Destination & Nombre de patients (total =37) \\
\hline Océanie & $\mathbf{4 ( 1 1 \% )}$ \\
$\quad$ Tahiti & 3 \\
$\quad$ Australie & 1 \\
\hline Amérique & $\mathbf{7 ( 1 9 \% )}$ \\
$\quad$ Caraïbes & \\
$\quad$ Guadeloupe & 2 \\
$\quad$ République Dominicaine & 2 \\
Amérique latine & \\
$\quad$ Brésil & \\
$\quad$ Mexique & 1 \\
& 2
\end{tabular}




\begin{tabular}{|c|c|}
\hline Destination & Nombre de patients (total $=37$ ) \\
\hline Asie & $14(38 \%)$ \\
\hline Sous-Continent indien & \\
\hline Inde & 1 \\
\hline Maldives & 3 \\
\hline Asie du Sud-Est & \\
\hline Vietnam & 1 \\
\hline Cambodge & 1 \\
\hline Thaïlande & 3 \\
\hline Malaisie & 2 \\
\hline Indonésie & 3 \\
\hline Afrique & $9(24 \%)$ \\
\hline Ile Maurice & 3 \\
\hline Rodrigues & 1 \\
\hline Réunion & 2 \\
\hline Madagascar & 1 \\
\hline Sénégal & 1 \\
\hline Egypte & 1 \\
\hline Europe & $3(8 \%)$ \\
\hline Grèce & 2 \\
\hline Monténégro & 1 \\
\hline
\end{tabular}

Tableau 1 : destinations de voyage des patients consultant pour envenimations marines

La durée médiane entre la date de l'envenimation et la consultation était de 14 jours (extrêmes 2 à 130 jours). La durée médiane entre la date de retour et la date de consultation était de 9 jours (extrêmes 0 à 120 jours).

\section{2- Envenimations par coraux}

Dans notre population, la première cause d'envenimation marine rencontrée était les blessures par coraux. Les caractéristiques cliniques initiales et lors de la consultation sont décrites ci-dessous.

\begin{tabular}{|l|c|c|c|c|c|c|c|}
\hline $\mathbf{N}^{\circ}$ & $\begin{array}{c}\text { Âge/ } \\
\text { sexe }\end{array}$ & $\begin{array}{c}\text { Lieu de } \\
\text { voyage }\end{array}$ & Activité & $\begin{array}{c}\text { Symptômes } \\
\text { immédiats }\end{array}$ & $\begin{array}{c}\text { Traitements } \\
\text { immédiats }\end{array}$ & $\begin{array}{c}\text { Constatations lors de } \\
\text { la consultation }\end{array}$ & $\begin{array}{c}\text { Traitements } \\
\text { prescrits lors de } \\
\text { la consultation }\end{array}$ \\
\hline 1 & $37 / \mathrm{M}$ & $\begin{array}{l}\text { Indonésie } \\
\text { (Bali) }\end{array}$ & Plongée & $\begin{array}{l}\text { Sensation de brûlure, } \\
\text { piqûre vive. } 8 \text { jours } \\
\text { après : majoration de } \\
\text { la sensation de } \\
\text { brûlure et léger } \\
\text { érythème }\end{array}$ & $\begin{array}{l}\text { Légère sensation de } \\
\text { brûlure, } \\
\text { érythème papuleux de } \\
1 \mathrm{~cm} \text { de diamètre }\end{array}$ & Bétaméthasone $6 \mathrm{j}$ \\
\hline
\end{tabular}




\begin{tabular}{|c|c|c|c|c|c|c|c|}
\hline $\mathbf{N}^{\circ}$ & $\begin{array}{l}\text { Âge/ } \\
\text { sexe }\end{array}$ & $\begin{array}{l}\text { Lieu de } \\
\text { voyage }\end{array}$ & Activité & $\begin{array}{l}\text { Symptômes } \\
\text { immédiats }\end{array}$ & $\begin{array}{l}\text { Traitements } \\
\text { immédiats }\end{array}$ & $\begin{array}{l}\text { Constatations lors de } \\
\text { la consultation }\end{array}$ & $\begin{array}{l}\text { Traitements } \\
\text { prescrits lors de } \\
\text { la consultation }\end{array}$ \\
\hline 2 & $26 / M$ & $\begin{array}{l}\text { Egypte (mer } \\
\text { rouge) }\end{array}$ & Plongée & $\begin{array}{l}\text { Main et genoux: } \\
\text { brûlure immédiate. } \\
\text { Disparition pendant } 2 \\
\text { jours, puis apparition } \\
\text { d'un érythème } \\
\text { violacé, papuleux, } \\
\text { prurigineux }\end{array}$ & Vinaigre & $\begin{array}{l}\text { Lésion érythémateuse, } \\
\text { vésiculeuse du genou } \\
\text { gauche, prurigineuse }\end{array}$ & $\begin{array}{l}\text { Bétaméthasone } 9 \mathrm{j} \\
\text { avec décroissance }\end{array}$ \\
\hline 3 & $36 / \mathrm{F}$ & $\begin{array}{l}\text { Thaillande, } \\
\text { Koh Phi Phi }\end{array}$ & PMT & $\begin{array}{l}\text { Pieds : douleur, } \\
\text { blessure avec } \\
\text { saignement }\end{array}$ & $\begin{array}{l}\text { Antiseptique } \\
\text { local et acide } \\
\text { fucidique } \\
\text { topique. } \\
\text { Extraction d'un } \\
\text { petit fragment } \\
\text { de corail d'une } \\
\text { plaie }\end{array}$ & $\begin{array}{l}\text { Douleur et prurit } \\
\text { important. } \\
\text { Plaies et éraflures } \\
\text { superficielles. Réaction } \\
\text { locale très limitée. Pas } \\
\text { de collection } \\
\text { fluctuante }\end{array}$ & $\begin{array}{l}\text { Quotane crème } \\
\text { (crème } \\
\text { anesthésique } \\
\text { anti-prurigineuse) }\end{array}$ \\
\hline 4 & $38 / \mathrm{M}$ & Brésil & PMT & $\begin{array}{l}\text { Douleur face } \\
\text { postérieure de la } \\
\text { cheville droite }\end{array}$ & & $\begin{array}{l}\text { Lésion superficielle, } \\
\text { prurigineuse, } \\
\text { érythémateuse, } \\
\text { propre. }\end{array}$ & $\begin{array}{l}\text { Nettoyage eau et } \\
\text { savon, } \\
\text { antihistaminiques }\end{array}$ \\
\hline 5 & $50 / \mathrm{M}$ & Maldives & & $\begin{array}{l}\text { Lésions de la face } \\
\text { postérieure des } 2 \\
\text { jambes. Apparition } \\
\text { secondaire de } \\
\text { dermabrasions } \\
\text { érythémateuses, et } \\
\text { impétigination }\end{array}$ & $\begin{array}{l}\text { Cefuroxime } \\
\text { axetil } 5 \text { jours, } \\
\text { paracétamol, } \\
\text { mupirocine } \\
\text { topique }\end{array}$ & $\begin{array}{l}\text { Prurit, cicatrisation } \\
\text { incomplète, croûtes }\end{array}$ & Bétaméthasone \\
\hline 6 & $39 / F$ & Thaïlande & & $\begin{array}{l}\text { CEdème des } 2 \text { jambes } \\
\text { et érythème }\end{array}$ & $\begin{array}{l}\text { Augmentin et } \\
\text { pristinamycine, } \\
\text { antihistamini- } \\
\text { que }\end{array}$ & $\begin{array}{l}\text { Placard érythémateux, } \\
\text { majoré en déclivité }\end{array}$ & $\begin{array}{l}\text { Dermocorticoides } \\
\text { Echo-doppler des } \\
\text { membres } \\
\text { inférieurs: } \\
\text { normal }\end{array}$ \\
\hline 7 & $54 / \mathrm{M}$ & Rodrigues & & $\begin{array}{l}\text { Lésion du } 2^{\mathrm{e}} \text { orteil du } \\
\text { pied } \mathrm{D}\end{array}$ & & $\begin{array}{l}\text { Inflammation modérée } \\
\text { de l'orteil: début de } \\
\text { dermohypodermite. }\end{array}$ & $\begin{array}{l}\text { Pristinamycine } \\
3 \mathrm{~g} / \mathrm{j} 7 \mathrm{j} . \\
\text { Radio des parties } \\
\text { molles }\end{array}$ \\
\hline 8 & $32 / \mathrm{F}$ & Guadeloupe & Plongée & $\begin{array}{l}\text { Érythème. } \\
\text { Amélioration puis } \\
\text { aggravation de la } \\
\text { douleur et de } \\
\text { l'œdème main D, } \\
\text { bras G, cheville G }\end{array}$ & $\begin{array}{l}\text { 5j après } \\
\text { l'envenimation : } \\
\text { méthylprédniso } \\
\text { lone IV, } \\
\text { dermocorti- } \\
\text { coïdes } \\
\end{array}$ & $\begin{array}{l}\text { Lésions linéaires cuisse } \\
\text { droite, érythème } \\
\text { cheville gauche, avant- } \\
\text { bras gauche, et paume } \\
\text { de main droite }\end{array}$ & Clobétasol 15j \\
\hline
\end{tabular}




\begin{tabular}{|c|c|c|c|c|c|c|c|}
\hline $\mathbf{N}^{\circ}$ & $\begin{array}{l}\text { Âge/ } \\
\text { sexe }\end{array}$ & $\begin{array}{l}\text { Lieu de } \\
\text { voyage }\end{array}$ & Activité & $\begin{array}{l}\text { Symptômes } \\
\text { immédiats }\end{array}$ & $\begin{array}{l}\text { Traitements } \\
\text { immédiats }\end{array}$ & $\begin{array}{l}\text { Constatations lors de } \\
\text { la consultation }\end{array}$ & $\begin{array}{l}\text { Traitements } \\
\text { prescrits lors de } \\
\text { la consultation }\end{array}$ \\
\hline 9 & $49 / F$ & Guadeloupe & PMT & $\begin{array}{l}\text { Douleur, éraflure. } 12 \mathrm{j} \\
\text { plus tard, apparition } \\
\text { d'une éruption. }\end{array}$ & $\begin{array}{l}\text { Aucun } \\
\text { immédiatement } \\
\text { 12j plus tard: } \\
\text { amoxicilline, } \\
\text { bétaméthasone, } \\
\text { antihistamini- } \\
\text { que, } \\
\text { antiseptique }\end{array}$ & $\begin{array}{l}\text { Plaque érythémateuse } \\
\text { émiettée vésiculeuse, } \\
\text { prurigineuse, } \\
\text { lichénoïde }\end{array}$ & $\begin{array}{l}\text { Clobétasol 15j. } \\
\text { Consultation 22j } \\
\text { plus tard : } \\
\text { disparition du } \\
\text { prurit. Atrophie } \\
\text { cutanée } \\
\text { modérée. } \\
\text { Pigmentation et } \\
\text { érythème } \\
\text { résiduel. }\end{array}$ \\
\hline 10 & $63 / F$ & Malaisie & Plongée & $\begin{array}{l}\text { Érythème, puis } \\
\text { apparition de } \\
\text { vésicules et œdème } \\
\text { de la main }\end{array}$ & $\begin{array}{l}\text { Hydroscortisone } \\
\text { topique }\end{array}$ & $\begin{array}{l}\text { CEdème de la main, } \\
\text { lésions vésiculeuses } \\
\text { multiples du dos de la } \\
\text { main }\end{array}$ & $\begin{array}{l}\text { Bétaméthasone, } \\
\text { valaciclovir } \\
500 \mathrm{mg} \times 2 / \mathrm{j} 5 \mathrm{j}, \\
\text { vaccin DTP } \\
\text { (PCR HSV } \\
\text { négative } \\
\text { finalement) } \\
\end{array}$ \\
\hline 11 & $38 / \mathrm{F}$ & Malaisie & & $\begin{array}{l}\text { Genou gauche: } \\
\text { érythème initial. } \\
\text { Secondairement } \\
\text { extension de } \\
\text { l'érythème à la face } \\
\text { externe du genou, } \\
\text { avec prurit intense, } \\
\text { œdème. }\end{array}$ & & $\begin{array}{l}\text { Lésion érythémateuse, } \\
\text { avec lésions de } \\
\text { grattage, suintante }\end{array}$ & $\begin{array}{l}\text { Bétaméthasone, } \\
\text { vaccin DTPc }\end{array}$ \\
\hline
\end{tabular}

Tableau 2 : caractéristiques des patients ayant eu une envenimation par coraux

Les patients 1 à 6 rapportent avoir été en contact avec des coraux «classiques », ou sans précision. Les patients 7 à 11 rapportent une envenimation par corail de feu.

Aucun de nos patients n'a eu de réaction systémique. Il est à noter que 6 patients sur 11 rapportent une évolution en deux temps : une dermite aigue qui s'amende rapidement, puis l'apparition quelques jours plus tard de nouvelles lésions. Nous reverrons ce phénomène dans la discussion.

Le traitement principal a été des dermocorticoïdes forts ou très forts pour 8 patients. Quatre patients ont reçu des antibiotiques par voie systémique après l'envenimation. L'évolution a globalement été favorable, puisqu'un seul patient a nécessité une consultation de suivi ultérieure.

\section{3- Envenimations par poissons-pierre}

Dix personnes ont consulté pour une envenimation par poisson-pierre. Les caractéristiques des patients et des envenimations sont décrites ci-dessous. 


\begin{tabular}{|c|c|c|c|c|c|c|c|}
\hline $\mathbf{N}^{\circ}$ & $\begin{array}{l}\text { Âge/ } \\
\text { sexe }\end{array}$ & $\begin{array}{l}\text { Lieu de } \\
\text { voyage }\end{array}$ & Symptômes immédiats & $\begin{array}{l}\text { Traitements } \\
\text { immédiats }\end{array}$ & $\begin{array}{l}\text { Délai } \\
\text { (1) }\end{array}$ & $\begin{array}{l}\text { Constatations lors de } \\
\text { la consultation }\end{array}$ & $\begin{array}{l}\text { Traitements } \\
\text { prescrits à la } \\
\text { consultation }\end{array}$ \\
\hline 1 & $42 / \mathrm{M}$ & Ile Maurice & $\begin{array}{l}\text { Douleur à la plante de } \\
4^{\mathrm{e}} \text { orteil du pied droit }\end{array}$ & $\begin{array}{l}\text { Anti venin IV, } \\
\text { hydrocortisone IV, } \\
\text { parage chirurgical, } \\
\text { amoxicilline et AINS }\end{array}$ & $4 j$ & $\begin{array}{l}\text { Plaie propre environ } \\
2 \mathrm{~cm} \text { de long, } \\
\text { bourgeonnant, pas } \\
\text { de nécrose. Intertrigo } \\
\text { inter orteil, orteil } \\
\text { chaud. }\end{array}$ & $\begin{array}{l}\text { Soins locaux. } \\
\text { Antifongique } \\
\text { local }\end{array}$ \\
\hline 2 & $57 / \mathrm{M}$ & Tahiti & $\begin{array}{l}\text { Douleur au pied droit } \\
\text { syncopale }\end{array}$ & $\begin{array}{l}\text { Immersion du pied } \\
\text { dans l'eau brulante } \\
\text { pendant } 1 \mathrm{~h} 30 . \\
\text { Augmentin, } \\
\text { antalgiques, } \\
\text { corticoïdes } 15 \mathrm{j}\end{array}$ & $17 \mathrm{j}$ & $\begin{array}{l}\text { Plaie propre, } \\
\text { légèrement indurée. } \\
\text { Pas de douleur, pas } \\
\text { d'œdème }\end{array}$ & $\begin{array}{l}\text { Bas de } \\
\text { contention, } \\
\text { poursuite } \\
\text { corticothérapie } \\
\text { pendant 10j }\end{array}$ \\
\hline 3 & $56 / \mathrm{F}$ & Ile Maurice & $\begin{array}{l}\text { Douleur au pied droit. } \\
\text { Secondairement } \\
\text { asthénie et myalgies }\end{array}$ & $\begin{array}{l}\text { Incision, sérum anti } \\
\text { venin, antibiotiques, } \\
\text { corticoïdes }\end{array}$ & $31 \mathrm{j}$ & $\begin{array}{l}\text { Douleur intense, } \\
\text { asthénie. CEdème du } \\
\text { pied, hallux } \\
\text { inflammatoire avec } \\
\text { lésion ulcérée } \\
\text { douloureuse }\end{array}$ & $\begin{array}{l}\text { Bas de } \\
\text { contention, } \\
\text { antalgiques de } \\
\text { pallier 2, } \\
\text { levofloxacine, } \\
\text { corticoïdes }\end{array}$ \\
\hline 4 & $58 / \mathrm{M}$ & Tahiti & $\begin{array}{l}\text { Douleur au niveau du } \\
\text { pied droit, œdème } \\
\text { jusqu'au genou. } \\
\text { Secondairement } \\
\text { diminution de } \\
\text { l'œdème, douleur } \\
\text { résiduelle }\end{array}$ & $\begin{array}{l}\text { Chaleur pendant } \\
1 \mathrm{~h} 30 \text {, antiseptique. } \\
\text { Pristinamycine } 3 \mathrm{~g} / \mathrm{j} 7 \mathrm{j} \\
\text { puis } 2 \mathrm{~g} / \mathrm{j} 12 \mathrm{j}\end{array}$ & $40 \mathrm{j}$ & $\begin{array}{l}\text { EFdème nocturne, } \\
\text { douleur. Pas de } \\
\text { nécrose }\end{array}$ & Aucun \\
\hline 5 & $37 / \mathrm{F}$ & $\begin{array}{l}\text { Inde - } \\
\text { Pondichéry }\end{array}$ & $\begin{array}{l}\text { Douleur intense du } \\
\text { pied } D \text { avec marche } \\
\text { impossible, } \\
\text { saignement au point } \\
\text { de piqûre, réaction } \\
\text { inflammatoire }\end{array}$ & $\begin{array}{l}\text { Antiseptique, } \\
\text { cicatrisation en } 5 \\
\text { jours, œdème de } \\
\text { cheville et douleur } \\
\text { diminués. } \\
\text { Secondairement } \\
\text { métronidazole }\end{array}$ & $12 \mathrm{j}$ & $\begin{array}{l}\text { Paresthésies à type } \\
\text { de picotement et } \\
\text { brûlures. CEdème du } \\
\text { pied, prurit, } \\
\text { érythème }\end{array}$ & $\begin{array}{l}\text { Augmentin } 1 \mathrm{~g} \\
\mathrm{x} 3 / \mathrm{j} \text { pendant } 10 \\
\text { jours }\end{array}$ \\
\hline 6 & $30 / \mathrm{F}$ & $\begin{array}{l}\text { Malaisie - } \\
\text { Kunantan }\end{array}$ & $\begin{array}{l}\text { Malaise, décharge } \\
\text { électrique, douleur } \\
\text { intense. } 3 \text { piqures } \\
\text { visibles à la face } \\
\text { plantaire du pied G. } \\
\text { Puis diminution des } \\
\text { paresthésies, } \\
\text { majoration de } \\
\text { l'œdème, difficultés à } \\
\text { la marche à cause des } \\
\text { douleurs }\end{array}$ & $\begin{array}{l}\text { Hydrocortisone, } \\
\text { morphine, } \\
\text { Augmentin }\end{array}$ & $2 j$ & $\begin{array}{l}\text { Éruption du tronc } \\
\text { non prurigineuse. } \\
\text { Pied oedématié, } \\
\text { douloureux à la } \\
\text { palpation, cyanosé, } \\
\text { froid. Paresthésies } \\
\text { des orteils }\end{array}$ & $\begin{array}{l}\text { Ofloxacine et } \\
\text { métronidazole } \\
\text { pendant } 7 \text { jours }\end{array}$ \\
\hline
\end{tabular}




\begin{tabular}{|c|c|c|c|c|c|c|c|}
\hline $\mathbf{N}^{\circ}$ & $\begin{array}{l}\text { Âge/ } \\
\text { sexe }\end{array}$ & $\begin{array}{l}\text { Lieu de } \\
\text { voyage }\end{array}$ & Symptômes immédiats & $\begin{array}{l}\text { Traitements } \\
\text { immédiats }\end{array}$ & $\begin{array}{l}\text { Délai } \\
\text { (1) }\end{array}$ & $\begin{array}{l}\text { Constatations lors de } \\
\text { la consultation }\end{array}$ & $\begin{array}{l}\text { Traitements } \\
\text { prescrits à la } \\
\text { consultation }\end{array}$ \\
\hline 7 & $43 / \mathrm{M}$ & Réunion & $\begin{array}{l}\text { Douleur violente du } \\
\text { pied droit. Important } \\
\text { œdème du pied }\end{array}$ & $\begin{array}{l}\text { Immersion dans l'eau } \\
\text { chaude. Puis } \\
\text { anesthésie locale }\end{array}$ & $10 \mathrm{j}$ & $\begin{array}{l}\text { CEdème du pied, } \\
\text { zone nécrotique de } \\
\text { l'hallux }\end{array}$ & $\begin{array}{l}\text { Pristinamycine } \\
1 \mathrm{~g} \times 3 / \mathrm{j} 7 \text { jours, } \\
\text { chaussettes de } \\
\text { contention }\end{array}$ \\
\hline 8 & $34 / F$ & Réunion & $\begin{array}{l}\text { Douleur face plantaire } \\
\text { du 2e orteil du pied G. } \\
\text { Puis œdème, chaleur } \\
\text { et érythème du pied. } \\
\text { Nécrose de la face } \\
\text { plantaire du 2e orteil }\end{array}$ & $\begin{array}{l}\text { Eau chaude, } \\
\text { paracétamol, } \\
\text { glaçage, anesthésie } \\
\text { en bague. } \\
\text { Hospitalisation à J+8: } \\
\text { débridement } \\
\text { chirurgical de la plaie } \\
\text { sous AL. Cefuroxime, } \\
\text { ibuprofène, } \\
\text { paracétamol. }\end{array}$ & $22 j$ & $\begin{array}{l}\text { CEdème de l'orteil } \\
\text { avec zone nécrotique } \\
\text { et coloration } \\
\text { brunâtre de la zone } \\
\text { excisée. CEdème du } \\
\text { pied et de la cheville. }\end{array}$ & $\begin{array}{l}\text { Augmentin } 1 g \\
\text { x3/j pendant } 8 \\
\text { jours, } \\
\text { pansement gras } \\
\text { par Jelonet }\end{array}$ \\
\hline 9 & $58 / \mathrm{F}$ & Maldives & Douleur du pied G & $\begin{array}{l}\text { Aucun } \\
\text { immédiatement. A } \\
\text { J+3 : Lyrica, } \\
\text { paracétamol, } \\
\text { tramadol. }\end{array}$ & $21 j$ & $\begin{array}{l}\text { Douleur du dos du } \\
\text { pied. Chaleur locale. } \\
\text { Plaie punctiforme du } \\
\text { 3e orteil. }\end{array}$ & $\begin{array}{l}\text { Poursuite } \\
\text { Lyrica, } \\
\text { paracétamol, } \\
\text { tramadol. Repos } \\
\text { et surélévation } \\
\text { de jambe. }\end{array}$ \\
\hline 10 & $39 / F$ & Ile Maurice & Douleur du pied D & $\begin{array}{l}\text { Eau chaude. Incision, } \\
\text { sérum anti-venin, } \\
\text { antibiotique. } \\
\text { Puis 2e sérum anti- } \\
\text { venin, morphine, } \\
\text { céfuroxime 5j, HBPM. } \\
\text { Puis AINS, céfixime. } \\
\text { Puis pristinamycine, } \\
\text { pansement alcoolisé. }\end{array}$ & $10 \mathrm{j}$ & $\begin{array}{l}\text { Pied oedématié } \\
\text { jusqu'à la cheville, } \\
\text { inflammatoire. } 2 \\
\text { points de piqûre. }\end{array}$ & $\begin{array}{l}\text { Pristinamycine } \\
2 \mathrm{~g} / \mathrm{j} 15 \mathrm{j}, \text { bas de } \\
\text { contention, kiné } \\
\text { de drainage } \\
\text { lymphatique }\end{array}$ \\
\hline
\end{tabular}

Tableau 3 : caractéristiques des patients piqués par poisson-pierre

(1) : délai entre l'envenimation et la consultation

Les envenimations par poisson-pierre ont parfois provoqué des complications à moyen ou long terme :

\begin{tabular}{|l|l|l|l|l|}
\hline $\mathbf{N}^{\circ}$ & $\begin{array}{c}\text { Réalisation d'une } \\
\text { imagerie }\end{array}$ & Avis spécialisé & \multicolumn{1}{|c|}{ Chirurgie } & \multicolumn{1}{c|}{ Consultations ultérieures } \\
\hline 1 & Non & Non & Oui initialement & $\begin{array}{l}\mathrm{J}+12 \text { : amélioration, bonne cicatrisation mais } \\
\text { inflammation locale et intertrigo. Prescription de } \\
\text { pristinamycine } 3 \mathrm{~g} / \mathrm{j}, \text { bifonazole, bas de contention. }\end{array}$ \\
\hline 2 & Non & Non & Non & $\begin{array}{l}\mathrm{J}+38 \text { : desquamation post éruptive, pas de signe } \\
\text { inflammatoire }\end{array}$ \\
\hline
\end{tabular}




\begin{tabular}{|c|c|c|c|c|}
\hline $\mathbf{N}^{\circ}$ & $\begin{array}{l}\text { Réalisation d'une } \\
\text { imagerie }\end{array}$ & Avis spécialisé & Chirurgie & Consultations ultérieures \\
\hline 3 & Non & Oui & $\begin{array}{l}\text { Oui. J+43: } \\
\text { excision large } \\
\text { avec fermeture } \\
\text { par lambeau }\end{array}$ & Non \\
\hline 4 & $\begin{array}{l}\text { Oui : IRM à J75: } \\
\text { pas d'ostéo-artrite. } \\
\text { IRM de contrôle } 2 \\
\text { mois après: } \\
\text { amélioration. }\end{array}$ & Oui & Non & $\begin{array}{l}\text { J+74: douleurs à la marche et à la station debout, } \\
\text { œdème et chaleur intermittents, non constatés. Douleur } \\
\text { localisée en un point au talon. } \\
\text { J+118: cicatrisation, persistance douleur à la marche. } \\
\text { Adressé au chirurgien orthopédique : } \\
\text { algoneurodystrophie }\end{array}$ \\
\hline 5 & Non & Non & Non & Non \\
\hline 6 & $\begin{array}{l}\text { Radio du pied : pas } \\
\text { de corps radio- } \\
\text { opaque. Doppler : } \\
\text { normal. }\end{array}$ & Non & Non & $\begin{array}{l}\text { J+4 : amélioration nette, diminution de l'œdème, } \\
\text { persistance douleur et chaleur. }\end{array}$ \\
\hline 7 & $\begin{array}{l}\text { Oui : après la fin du } \\
\text { traitement } \\
\text { antibiotique }\end{array}$ & Oui & Non & J+16 : diminution de l'infection, enkystement. \\
\hline 8 & Non & Oui & Oui initialement & $\begin{array}{l}\text { J+32: zone nécrotique stable, pas de cellulite. arrêt des } \\
\text { pansements gras. Proposition d'excision des peaux } \\
\text { mortes, pansement sec. } \\
\text { J+52: amélioration de la nécrose, pas de signe de } \\
\text { surinfection, toujours pas cicatrisé. Chaussettes de } \\
\text { contention. }\end{array}$ \\
\hline 9 & Non & Non & Non & Non \\
\hline 10 & Non & Non & Oui initialement & $\begin{array}{l}\mathrm{J}+24 \text { : pied un peu chaud, oedématié, douloureux à la } \\
\text { palpation profonde. Reprise pristinamycine } 4 \mathrm{~g} / \mathrm{j} \text { pendant } \\
10 \mathrm{j} . \\
\mathrm{J}+59 \text { : guérison mais œedème si ne met pas les bas de } \\
\text { contention }\end{array}$ \\
\hline
\end{tabular}

Tableau 4 : caractéristiques de l'évolution des patients piqués par poisson-pierre 


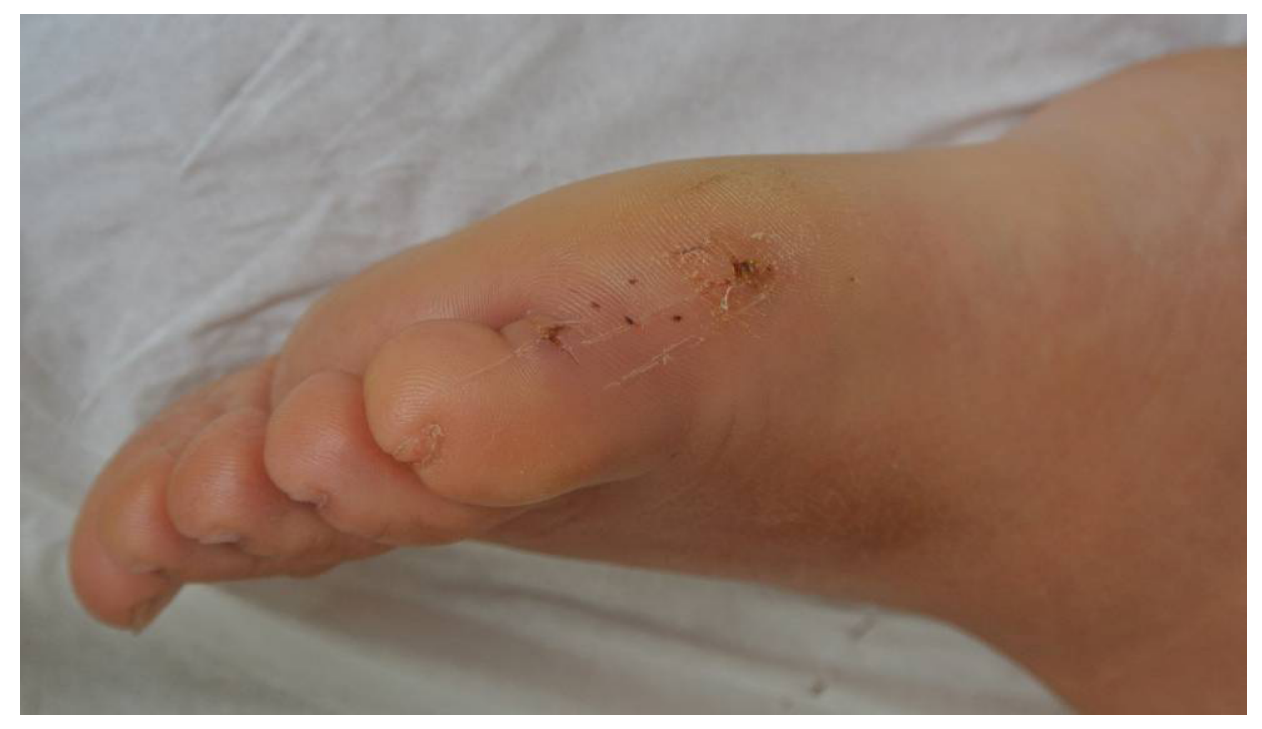

Figure 2 : envenimation par poisson-pierre à $\mathbf{J}+10$, patiente 10.

Les traitements initiaux ont consisté en une immersion dans l'eau chaude pour 5 patients sur 10, et 3 ont bénéficié du sérum anti venin. Ces patient sont ceux ayant voyagé à l'Ile Maurice, à la Réunion ou à Tahiti. Cela montre que ces envenimations sont connues dans ces régions et correctement prises en charge. Cela n'a pas été le cas dans les autres parties du monde.

On voit que les envenimations par poisson-pierre sont compliquées. Neuf des 10 patients ont reçu une antibiothérapie systémique. Sept patients ont eu au moins une deuxième consultation de suivi dans le service, et 4 ont été adressés à un spécialiste. Quatre patients ont été opérés initialement ou au cours du suivi.

\section{4- Envenimation par méduses}

Huit personnes ont consulté pour une envenimation par méduse. Les caractéristiques des patients et des envenimations sont décrites ci-dessous. 


\begin{tabular}{|c|c|c|c|c|c|c|c|c|}
\hline$\stackrel{\mathbf{N}}{\mathrm{N}}$ & $\begin{array}{l}\text { Âge/ } \\
\text { sexe }\end{array}$ & $\begin{array}{l}\text { Lieu de } \\
\text { voyage }\end{array}$ & $\begin{array}{c}\text { Cause } \\
\text { supposée }\end{array}$ & $\begin{array}{l}\text { Symptômes } \\
\text { immédiats }\end{array}$ & $\begin{array}{l}\text { Traitement } \\
\text { immédiat }\end{array}$ & $\begin{array}{c}\text { Délai } \\
\text { (1) }\end{array}$ & $\begin{array}{l}\text { Constatations lors de la } \\
\text { consultation }\end{array}$ & $\begin{array}{l}\text { Traitements } \\
\text { lors de la } \\
\text { consultation }\end{array}$ \\
\hline 1 & $67 / F$ & Vietnam & Méduse & $\begin{array}{l}\text { Douleur fulgurante } \\
\text { des bras et genou } \\
\text { D, à type de } \\
\text { décharge } \\
\text { électrique, brûlure. } \\
\text { Fièvre, sueurs, } \\
\text { nausées, } \\
\text { vomissement, } \\
\text { prurit. }\end{array}$ & $\begin{array}{l}\text { Vinaigre, eau } \\
\text { douce, } \\
\text { paracétamol } \\
\text { antibiotique } \\
\text { Puis } \\
\text { bétaméthaso- } \\
\text { ne }\end{array}$ & $15 j$ & $\begin{array}{l}\text { Lacérations des } 2 \text { bras } \\
\text { avec perte de substance. } \\
\text { Prurit intense, sensation } \\
\text { de brûlure et de cuisson. } \\
\text { Épanchement du genou, } \\
\text { flexion limitée, chaleur, } \\
\text { pas d'érythème. }\end{array}$ & $\begin{array}{l}\text { Bétaméthasone } \\
\text { Adressée en } \\
\text { consultation de } \\
\text { rhumatologie. }\end{array}$ \\
\hline 2 & $27 / F$ & $\begin{array}{l}\text { Républi- } \\
\text { que } \\
\text { Domini- } \\
\text { caine }\end{array}$ & Méduse & $\begin{array}{l}\text { Douleur de cheville } \\
\text { et cuisse D. Lésions } \\
\text { oedématiées, } \\
\text { violacées, avec } \\
\text { fièvre, diarrhée, } \\
\text { vomissements. } \\
\text { Évolution vers } \\
\text { l'ulcération des } \\
\text { lésions. }\end{array}$ & $\begin{array}{l}\text { Bétamétha- } \\
\text { sone }\end{array}$ & $21 j$ & $\begin{array}{l}\text { Lésions linéaires, } \\
\text { papuleuses, } \\
\text { érythémateuses. }\end{array}$ & $\begin{array}{l}\text { Bilan standard } \\
\text { normal. } \\
\text { Sérologies VHA } \\
\text { VHB VHC } \\
\text { négatives. }\end{array}$ \\
\hline 3 & $41 / \mathrm{M}$ & $\begin{array}{l}\text { Thaï- } \\
\text { lande }\end{array}$ & Méduse & $\begin{array}{l}\text { Bras G : lésion } \\
\text { érythémateuse, } \\
\text { papuleuse, en } \\
\text { extension. }\end{array}$ & & $9 j$ & $\begin{array}{l}\text { Lésion suintante, } \\
\text { prurigineuse, violacée au } \\
\text { centre, blanchâtre au } \\
\text { pourtour. }\end{array}$ & Bétaméthasone \\
\hline 4 & $60 / M$ & Mexi-que & Méduse & & & $14 j$ & $\begin{array}{l}\text { Lésion érythémateuse } \\
\text { linéaire }\end{array}$ & Bétaméthasone \\
\hline 5 & $55 / F$ & Mexi-que & Méduse & & & $14 j$ & $\begin{array}{l}\text { Trajet serpigineux avec } \\
\text { sensation de brûlure }\end{array}$ & $\begin{array}{l}\text { Ivermectine et } \\
\text { bétaméthasone }\end{array}$ \\
\hline 6 & $67 / M$ & Austra-lie & Irukandji & $\begin{array}{l}\text { 45min plus tard: } \\
\text { HTA, myalgies, } \\
\text { céphalées, } \\
\text { vomissements, toux }\end{array}$ & Vinaigre & 130j & $\begin{array}{l}\text { HTA, inquiétude quant } \\
\text { au risque d'allergie } \\
\text { croisée avec les } \\
\text { hyménoptères, angoisse. }\end{array}$ & Aucun \\
\hline
\end{tabular}




\begin{tabular}{|c|c|c|c|c|c|c|c|c|}
\hline $\mathbf{N}$ & $\begin{array}{l}\text { Âge/ } \\
\text { sexe }\end{array}$ & $\begin{array}{l}\text { Lieu de } \\
\text { voyage }\end{array}$ & $\begin{array}{l}\text { Cause } \\
\text { supposée }\end{array}$ & $\begin{array}{l}\text { Symptômes } \\
\text { immédiats }\end{array}$ & $\begin{array}{l}\text { Traitement } \\
\text { immédiat }\end{array}$ & $\begin{array}{l}\text { Délai } \\
\text { (1) }\end{array}$ & $\begin{array}{c}\text { Constatations lors de la } \\
\text { consultation }\end{array}$ & $\begin{array}{l}\text { Traitements } \\
\text { lors de la } \\
\text { consultation }\end{array}$ \\
\hline 7 & $41 / M$ & $\begin{array}{l}\text { Cambod- } \\
\text { ge }\end{array}$ & $\begin{array}{l}\text { Cubo- } \\
\text { méduse }\end{array}$ & $\begin{array}{l}\text { CEdème puis } \\
\text { douleur au niveau } \\
\text { du membre } \\
\text { supérieur D et } \\
\text { scapula D. }\end{array}$ & $\begin{array}{l}\text { Automédica- } \\
\text { tion par } \\
\text { corticothéra- } \\
\text { pie pendant } 2 \\
\text { à 3j } \\
\text { Consulte à J4 : } \\
\text { AINS et } \\
\text { Augmentin } \\
3 \mathrm{~g} / \mathrm{j}\end{array}$ & $7 \mathrm{j}$ & $\begin{array}{l}\text { CEdème majeur du bras } \\
\text { avec dermabrasions de } \\
\text { la scapula et de la face } \\
\text { antérieure de l'avant- } \\
\text { bras. Adénomégalie } \\
\text { sensible axillaire } D \text {. } \\
\text { Discrète infiltration de la } \\
\text { paroi abdominale. }\end{array}$ & 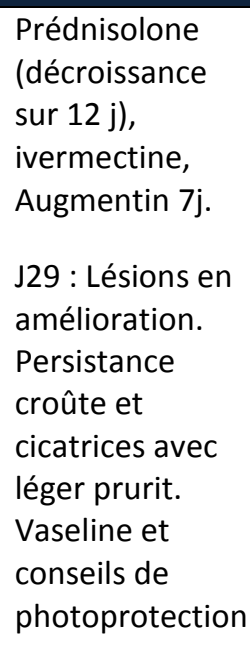 \\
\hline 8 & $68 / \mathrm{M}$ & $\begin{array}{l}\text { Madagas } \\
\text { car }\end{array}$ & Physalie & $\begin{array}{l}\text { Lésions } \\
\text { urticariennes des } \\
\text { fesses et abdomen. } \\
\text { Anxiété majeure, } \\
\text { HTA. } \\
\text { J9 : fièvre, diarrhée, } \\
\text { courbatures, puis } \\
\text { pertes appétit, } \\
\text { vertiges. }\end{array}$ & & $25 \mathrm{j}$ & $\begin{array}{l}\text { Quasi disparition des } \\
\text { lésions cutanées }\end{array}$ & $\begin{array}{l}\text { Aucun. } \\
\text { Réalisation d'un } \\
\text { bilan } \\
\text { biologique, sans } \\
\text { particularité. }\end{array}$ \\
\hline
\end{tabular}

Tableau 5 : caractéristiques des patients piqués par méduses

(1) : délai entre l'envenimation et la consultation

On constate dans ce tableau la grande variété clinique des envenimations par méduse, dans les symptômes immédiats, et dans les lésions vues à distance de l'envenimation. Les patients piqués par cuboméduse ou physalie ont tous rapportés des signes systémiques, tout comme 2 autres patients piqués par des méduses non précisées. Il peut ne persister que des lésions peu importantes, comme pour les patients $2,3,4,5$ ou 8.

Les dermocorticoïdes ont été prescrits dans 5 cas sur 8 . Une corticothérapie générale a été prescrite chez le patient piqué par cuboméduse, et les antibiotiques chez 2 patients. 


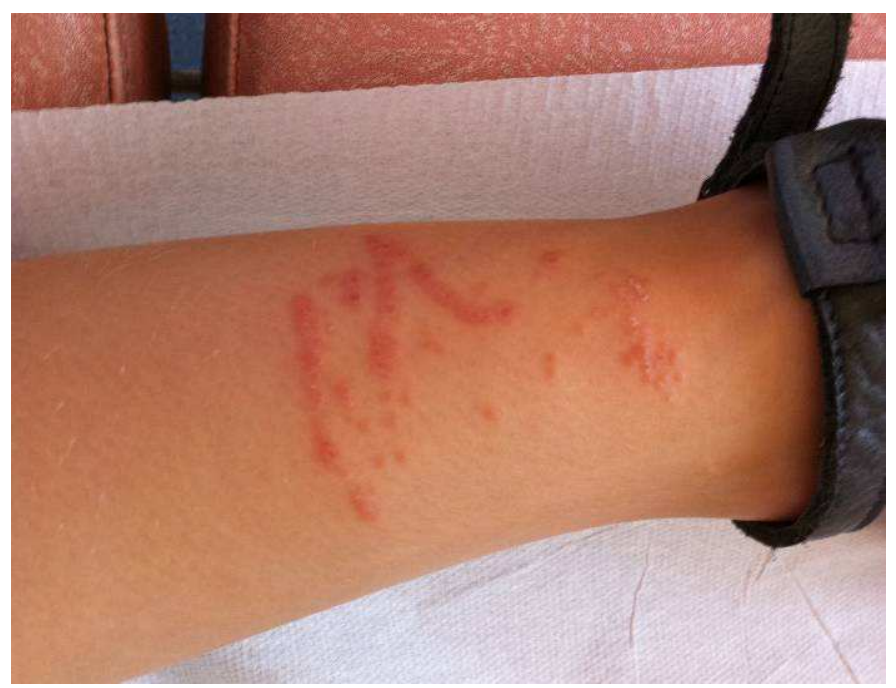

Figure 3 : piqure par méduse, patiente 2.

Les conséquences peuvent être plus graves, comme pour le patient 7 , dont le cas a fait l'objet d'une publication antérieure.(15) Les séquelles cutanées sont ici majeures.

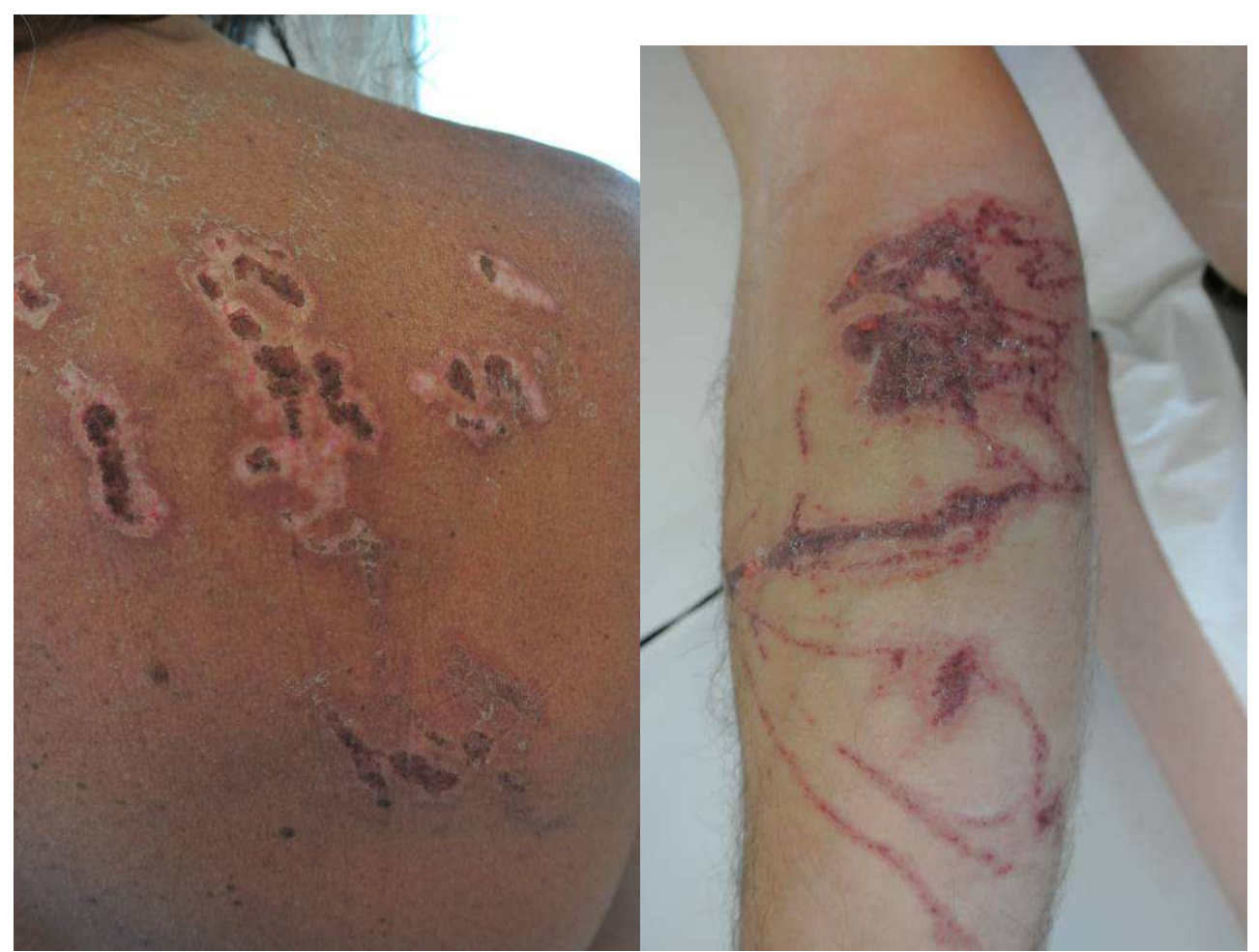

Figure 4 : J7 d'une envenimation marine par cuboméduse, patient 7, dos et bras.

Le cas du patient 6 est intéressant : après une piqûre par méduse Irukandji, sans séquelle, ce patient est littéralement traumatisé, et consulte 130 jours après l'envenimation. Il avait bénéficié du traitement de référence, le vinaigre, d'une prise en charge adaptée en Australie, mais il a tout de même recourt à une consultation spécialisée 4 mois après son retour. 


\section{5- Autres envenimations}

Les autres causes d'envenimation marines incluent 2 cas par vives, 2 cas par étoiles de mer, 2 cas par raies, un cas par poisson lion, un cas par anémone de mer. Globalement les conséquences sont essentiellement locales.

\begin{tabular}{|c|c|c|c|c|c|c|c|c|}
\hline $\mathbf{N}^{\circ}$ & $\begin{array}{l}\text { Âge/ } \\
\text { sexe }\end{array}$ & $\begin{array}{l}\text { Lieu de } \\
\text { voyage }\end{array}$ & $\begin{array}{l}\text { Délai } \\
\text { (1) }\end{array}$ & $\begin{array}{c}\text { Cause } \\
\text { supposée }\end{array}$ & $\begin{array}{l}\text { Symptômes } \\
\text { immédiats }\end{array}$ & $\begin{array}{l}\text { Traitements } \\
\text { immédiats }\end{array}$ & $\begin{array}{l}\text { Constatations lors } \\
\text { de la consultation }\end{array}$ & $\begin{array}{l}\text { Traitements lors } \\
\text { de la consultation }\end{array}$ \\
\hline 1 & $\begin{array}{l}50 / \\
M\end{array}$ & Sénégal & $12 \mathrm{j}$ & Raie & $\begin{array}{l}\text { Plaie à la face } \\
\text { interne du pied D. } \\
\text { CEdème au bout } \\
\text { de } 48 \mathrm{~h} \text {, en } \\
\text { amélioration } \\
\text { après 6j. } \\
\text { J9 : douleurs. }\end{array}$ & $\begin{array}{l}\text { Points de suture, } \\
\text { automédication } \\
\text { par Augmentin } \\
\mathrm{J} 9 \text { : Augmentin } \\
3 \mathrm{~g} / \mathrm{j} \text {, colchicine } \\
\text { paracétamol+ } \\
\text { tramadol }\end{array}$ & $\begin{array}{l}\text { Lésion cicatrisée de } \\
3 \mathrm{~cm} \text {, un peu } \\
\text { violacée avec } \\
\text { discret œedème } \\
\text { inflammatoire. }\end{array}$ & $\begin{array}{l}\text { Augmentin } 1 \mathrm{~g} \times 3 / \mathrm{j} \\
8 \mathrm{j} \text { au total, Ixprim, } \\
\text { arrêt de la } \\
\text { colchicine, bas de } \\
\text { contention. }\end{array}$ \\
\hline 2 & $26 / F$ & Indonésie & $12 j$ & Raie & $\begin{array}{l}\text { Douleur de la } \\
\text { cheville G, } \\
\text { malléole externe. }\end{array}$ & $\begin{array}{l}\text { Application d'une } \\
\text { plante locale, } \\
\text { antalgiques, AINS. } \\
\text { Aggravation J10: } \\
\text { antibiotiques. }\end{array}$ & $\begin{array}{l}\text { CEdème cheville et } \\
\text { érythème de la } \\
\text { malléole externe. } \\
\text { Plaie de } 5 \mathrm{~mm} \text { en } \\
\text { voie de } \\
\text { cicatrisation. }\end{array}$ & $\begin{array}{l}\text { Antihistaminiques } \\
\text { AINS, rappel DTP, } \\
\text { bas de } \\
\text { contention. } \\
\text { Échographie et } \\
\text { radio : pas de } \\
\text { corps étranger. } \\
\text { J29 : persistance } \\
\text { d'une zone } \\
\text { croûteuse, } \\
\text { indurée. } \\
\text { Prescription de } \\
\text { pristinamycine } \\
4 \text { g/j et acide } \\
\text { fucidique } \\
\text { pommade. } \\
\text { Épisodes } \\
\text { d'œdème } \\
\text { fluctuant sur 3-4j. } \\
\text { J55 : disparition } \\
\text { de la croûte, } \\
\text { œdème } \\
\text { persistant après } \\
\text { station debout } \\
\text { prolongée avec } \\
\text { signes } \\
\text { systémiques } \\
\text { (nausées, } \\
\text { paresthésies de la } \\
\text { jambe). }\end{array}$ \\
\hline 3 & $28 / \mathrm{F}$ & Grèce & $15 j$ & Vive & $\begin{array}{l}\text { Lésion du } 4 \mathrm{e} \\
\text { orteil du pied G } \\
\text { douleur, } \\
\text { inflammation. }\end{array}$ & $\begin{array}{l}\text { Immédiate-ment : } \\
\text { eau chaude }\end{array}$ & $\begin{array}{l}\text { Orteil } \\
\text { inflammatoire, avec } \\
\text { lésion violacée. }\end{array}$ & $\begin{array}{l}\text { Échographie : pas } \\
\text { de corps } \\
\text { étranger. } \\
\text { Augmentin } 1 \mathrm{gx} 3 / \mathrm{j} \\
8 \mathrm{j} \text {, paracétamol+ }\end{array}$ \\
\hline
\end{tabular}




\begin{tabular}{|c|c|c|c|c|c|c|c|c|}
\hline $\mathbf{N}^{\circ}$ & $\begin{array}{l}\text { Âge/ } \\
\text { sexe }\end{array}$ & $\begin{array}{l}\text { Lieu de } \\
\text { voyage }\end{array}$ & $\begin{array}{l}\text { Délai } \\
\text { (1) }\end{array}$ & $\begin{array}{l}\text { Cause } \\
\text { supposée }\end{array}$ & $\begin{array}{l}\text { Symptômes } \\
\text { immédiats }\end{array}$ & $\begin{array}{l}\text { Traitements } \\
\text { immédiats }\end{array}$ & $\begin{array}{l}\text { Constatations lors } \\
\text { de la consultation }\end{array}$ & $\begin{array}{c}\text { Traitements lors } \\
\text { de la consultation }\end{array}$ \\
\hline & & & & & & & & $\begin{array}{l}\text { tramadol, } \\
\text { antihistaminique, } \\
\text { vaccination DTPc. } \\
\text { J20: diminution } \\
\text { de l'œdème et de } \\
\text { la douleur. }\end{array}$ \\
\hline 4 & $\begin{array}{l}43 / \\
M\end{array}$ & $\begin{array}{l}\text { Monténé } \\
\text { gro }\end{array}$ & $10 \mathrm{j}$ & Vive & $\begin{array}{l}\text { Douleur intense } \\
\text { pied } D \text {, œdème. } \\
\text { Persistance de } \\
\text { l'œdème } 3 \text { jours, } \\
\text { puis surinfection. }\end{array}$ & & $\begin{array}{l}\text { Pas de signe } \\
\text { inflammatoire. } \\
\text { Bulle du 1er espace } \\
\text { interorteil. }\end{array}$ & Antalgiques \\
\hline 5 & $36 / \mathrm{F}$ & Indonésie & $14 j$ & $\begin{array}{l}\text { Etoile de } \\
\text { mer }\end{array}$ & Piqûre des doigts & $\begin{array}{l}\text { Eau chaude, } \\
\text { huiles } \\
\text { essentielles. } \\
\text { Augmentin } 5 \mathrm{j} \text { et } \\
\text { antihistaminique. }\end{array}$ & $\begin{array}{l}\text { Lésions en voie de } \\
\text { cicatrisation, pas } \\
\text { d'adénopathie. }\end{array}$ & $\begin{array}{l}\text { Radio : pas de } \\
\text { corps étranger } \\
\text { Augmentin } 1 \mathrm{gx} / \mathrm{j} \\
10 \mathrm{j} .\end{array}$ \\
\hline 6 & $\begin{array}{l}47 / \\
M\end{array}$ & Tahiti & $24 j$ & $\begin{array}{l}\text { Etoile de } \\
\text { mer } \\
\text { (Acanthas- } \\
\text { ter) }\end{array}$ & $\begin{array}{l}\text { Douleur } \\
\text { immédiate et } \\
\text { intense du pouce. }\end{array}$ & $\begin{array}{l}\text { Application de } \\
\text { citron vert. } \\
\text { Augmentin } 8 \mathrm{j}+ \\
\text { Biseptine et } \\
\text { flammazine }\end{array}$ & $\begin{array}{l}\text { Pulpe du pouce un } \\
\text { peu inflammatoire, } \\
\text { douloureuse, sans } \\
\text { signe de dermo- } \\
\text { hypodermite. } \\
\text { Douleur du coude. }\end{array}$ & AINS \\
\hline 7 & $52 / \mathrm{F}$ & $\begin{array}{l}\text { Grèce } \\
\text { (Milos) }\end{array}$ & $24 j$ & $\begin{array}{l}\text { Anémone } \\
\text { de mer }\end{array}$ & $\begin{array}{l}\text { Douleur vive puis } \\
\text { sensation de } \\
\text { brûlure de la } \\
\text { fesse G. Puis } \\
\text { apparition d'un } \\
\text { œdème avec } \\
\text { centre violacé. }\end{array}$ & $\begin{array}{l}\text { Apaysil. } \\
\text { Augmentin 1,5g/j } \\
5 \mathrm{j} \text {, antalgiques, } \\
\text { rappel DTP. } \\
\mathrm{J3} \text { : tramadol IV. } \\
\text { Mise sous } \\
\text { Augmentin } 3 \mathrm{~g} / \mathrm{j} \text { et } \\
\text { paracétamol + } \\
\text { tramadol. } \\
\mathrm{J} 4 \text { : bétamétha- } \\
\text { sone, } \\
\text { prégabaline, } \\
\text { pristinamycine } \\
\text { J5: bétamétha- } \\
\text { sone, laluset, et } \\
\text { acide fucidique } \\
\text { topique. }\end{array}$ & $\begin{array}{l}\text { Lésion croûteuse } \\
\text { sur placard } \\
\text { érythémateux. } \\
\text { Apyrétique }\end{array}$ & $\begin{array}{l}\text { NFS normale, CRP } \\
18 \mathrm{mg} / \mathrm{L} \text {. } \\
\text { Flammazine. } \\
\text { J32 : Lésions en } \\
\text { cours de } \\
\text { cicatrisation. } \\
\text { Encore quelques } \\
\text { croûtes. Quelques } \\
\text { jours de } \\
\text { flammazine puis } \\
\text { vaseline. } \\
\text { Poursuite } \\
\text { prégabaline pour } \\
\text { douleurs. } \\
\text { J41 : cicatrisation } \\
\text { complète, } \\
\text { adressée à } \\
\text { l'équipe de la } \\
\text { douleur. }\end{array}$ \\
\hline 8 & $\begin{array}{l}25 / \\
M\end{array}$ & $\begin{array}{l}\text { Républi- } \\
\text { que } \\
\text { Domini- } \\
\text { caine }\end{array}$ & $11 \mathrm{j}$ & $\begin{array}{l}\text { Poisson- } \\
\text { lion }\end{array}$ & $\begin{array}{l}\text { Douleurs intenses } \\
\text { du pied G, } \\
\text { œdème, } \\
\text { érythème. } \\
\text { Puis diminution }\end{array}$ & $\begin{array}{l}\text { Perfusion, } \\
\text { solumedrol } \\
\text { 1000mg, } \\
\text { Hydrocorti-sone, } \\
\text { antihistami-nique, }\end{array}$ & $\begin{array}{l}\text { CEdème en fin de } \\
\text { journée, pas } \\
\text { d'inflammation } \\
\text { locale. } \\
4 \text { lésions }\end{array}$ & $\begin{array}{l}\text { Bas de } \\
\text { contention, } \\
\text { paracétamol } \\
\text { codéiné. }\end{array}$ \\
\hline
\end{tabular}




\begin{tabular}{|l|l|l|l|l|l|l|l|l|}
\hline $\mathbf{N}^{\circ}$ & $\begin{array}{l}\text { Âge/ } \\
\text { sexe }\end{array}$ & $\begin{array}{c}\text { Lieu de } \\
\text { voyage }\end{array}$ & $\begin{array}{c}\text { Délai } \\
(\mathbf{1})\end{array}$ & $\begin{array}{c}\text { Cause } \\
\text { supposée }\end{array}$ & $\begin{array}{c}\text { Symptômes } \\
\text { immédiats }\end{array}$ & $\begin{array}{c}\text { Traitements } \\
\text { immédiats }\end{array}$ & $\begin{array}{l}\text { Constatations lors } \\
\text { de la consultation }\end{array}$ & $\begin{array}{c}\text { Traitements lors } \\
\text { de la consultation }\end{array}$ \\
\hline & & & & & $\begin{array}{l}\text { des douleurs, } \\
\text { persistance } \\
\text { edème et } \\
\text { érythème. }\end{array}$ & $\begin{array}{l}\text { AlNS, ceftriaxone } \\
1 \mathrm{~g} / \mathrm{j} .\end{array}$ & $\begin{array}{l}\text { ponctiformes et } \\
\text { discret érythème. }\end{array}$ & \\
\hline
\end{tabular}

Tableau 6 : caractéristiques des patients ayant d'autres causes d'envenimation marine

(1) : délai entre l'envenimation et la consultation

Ces envenimations étant diverses, leur présentation l'est également. On constate qu'il y a eu une surinfection des lésions avec prescription d'antibiothérapies systémiques chez les 2 patients piqués par des raies, un des 2 patients piqués par vive, les 2 patients piqués par étoiles de mer, la patiente piquée par anémone de mer et celui par poisson-lion.

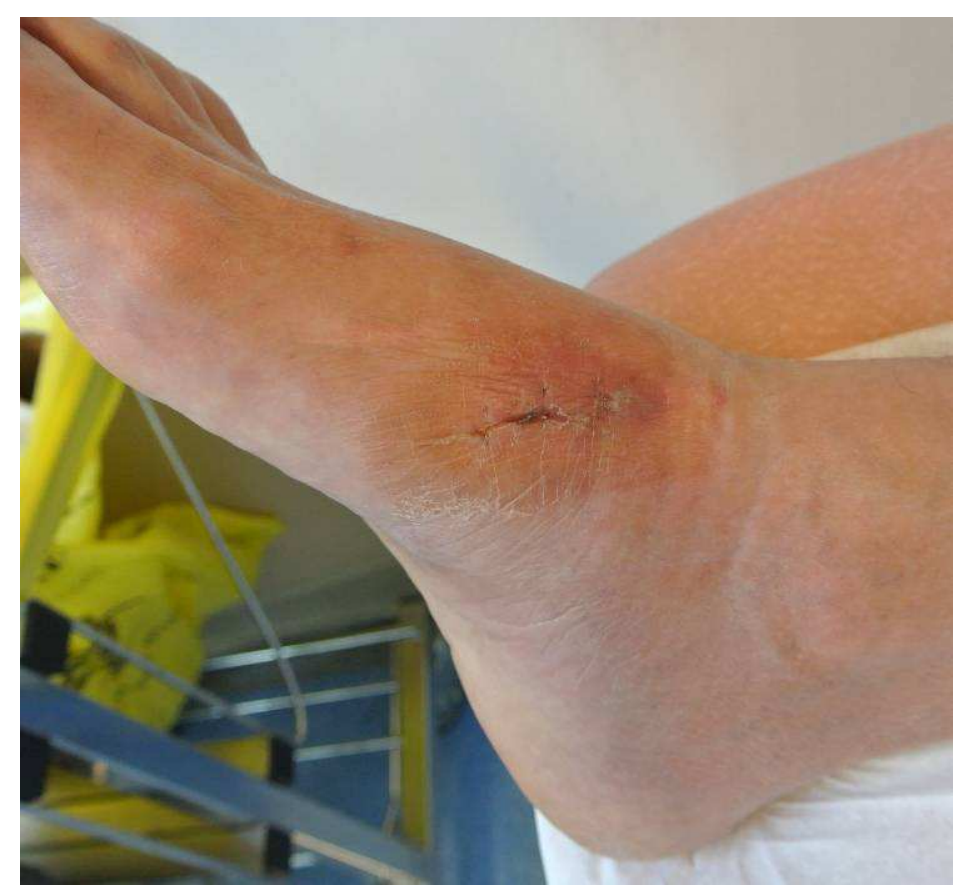

Figure 5 : piqûre par raie vue à J12, patient 1 . 


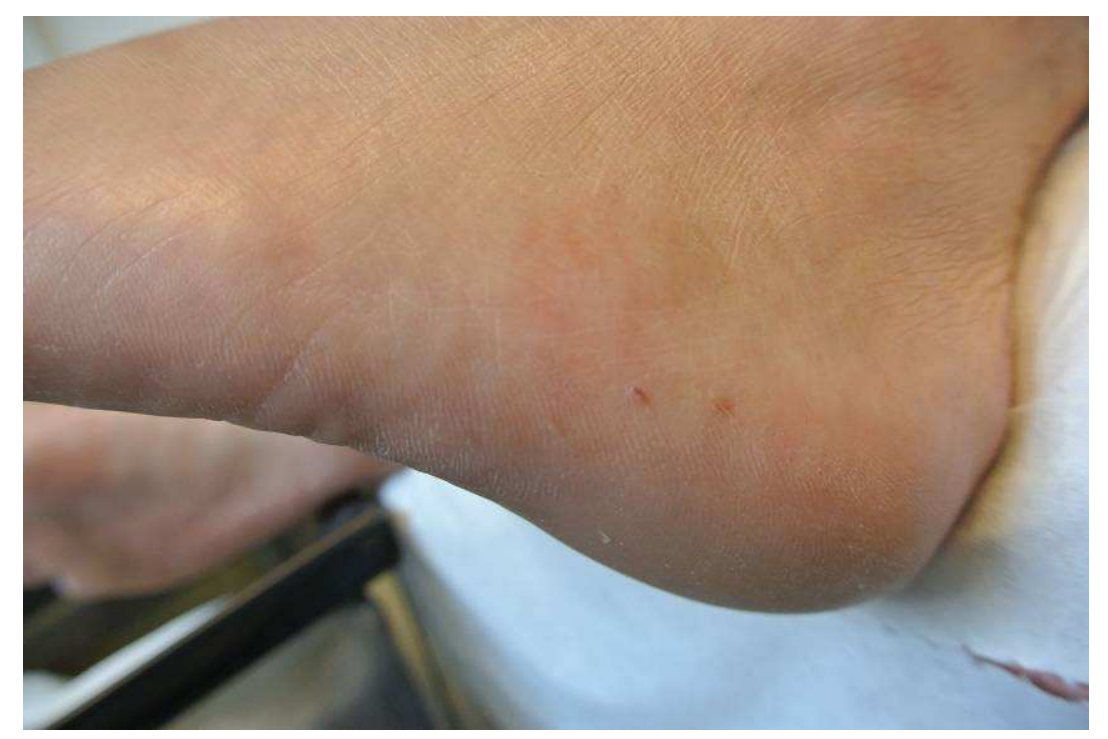

Figure 6 : piqûre par poisson-lion, vue à J15, patient 8.

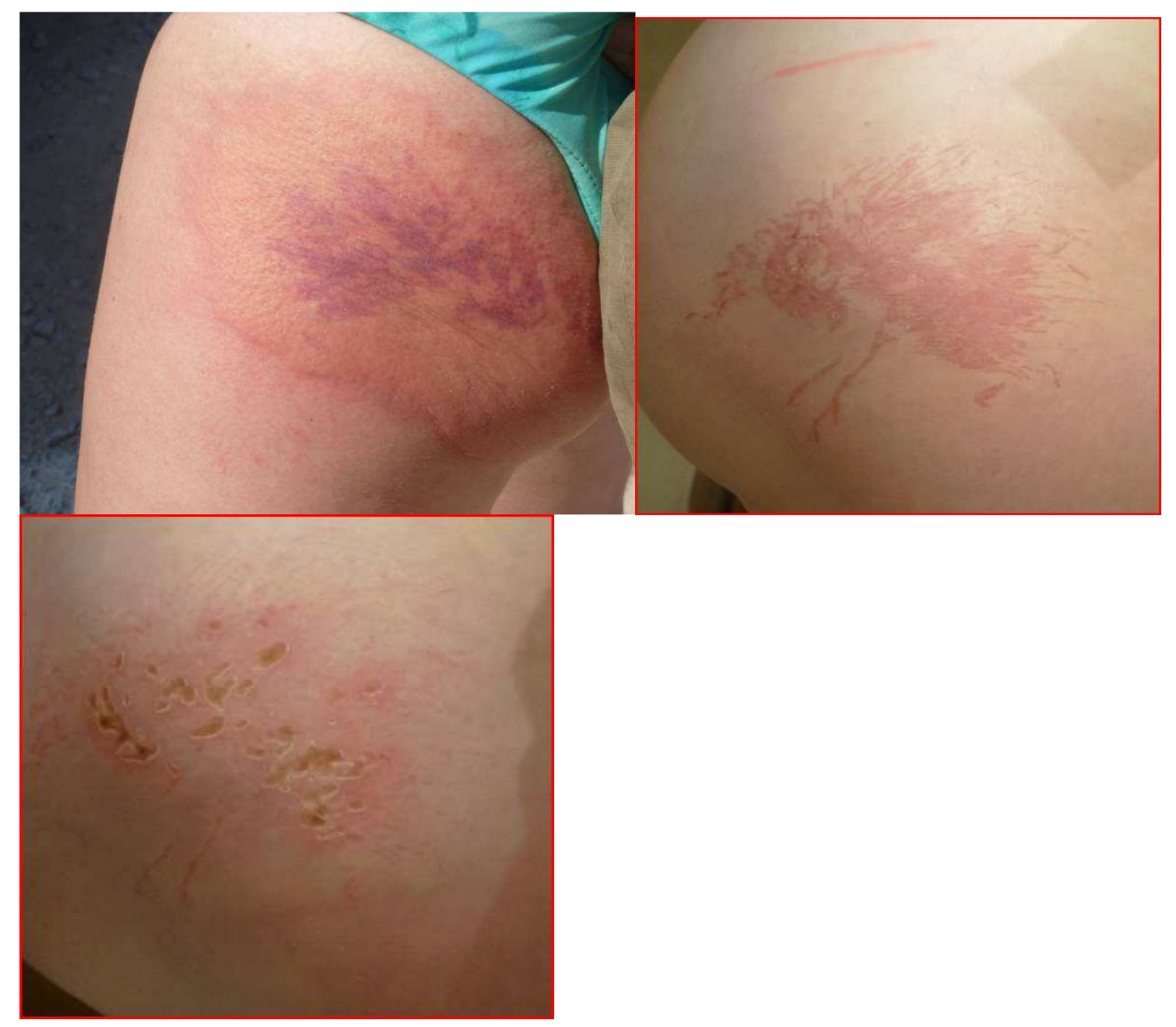

Figure 7: envenimation par anémone de mer, patiente 7. A 30min, J5 puis J16. 


\section{6- Constatations générales}

On remarque que ces consultations post-voyage ont été l'occasion de remettre à jour la vaccination DTP dans 4 cas sur 37. Ceci n'aurait bien sûr pas dû avoir lieu : la mise à jour des vaccins habituels est nécessaire d'une manière générale, et encore plus en cas de consultation pré-voyage. 


\section{Discussion :}

L'étude du spectre des envenimations marines chez le voyageur montre que l'envenimation par coraux est la plus fréquente, devant les poissons pierre et les méduses. Enfin on retrouve quelques cas d'envenimations par vive, étoiles de mer, raies, ou de manière anecdotique poisson lion et anémone de mer. Un suivi à long terme a été possible lorsque cela s'est avéré nécessaire.

\section{1- Envenimations marines rencontrées dans notre étude}

Les envenimations marines les plus fréquentes sont dues aux Cnidaires. L'embranchement des Cnidaires se divise en quatre classes : Anthozoa (coraux, anémones de mer), Hydrozoa (physalies, coraux de feu), Schiphozoa (méduses), et Cubozoa (médusesboites).

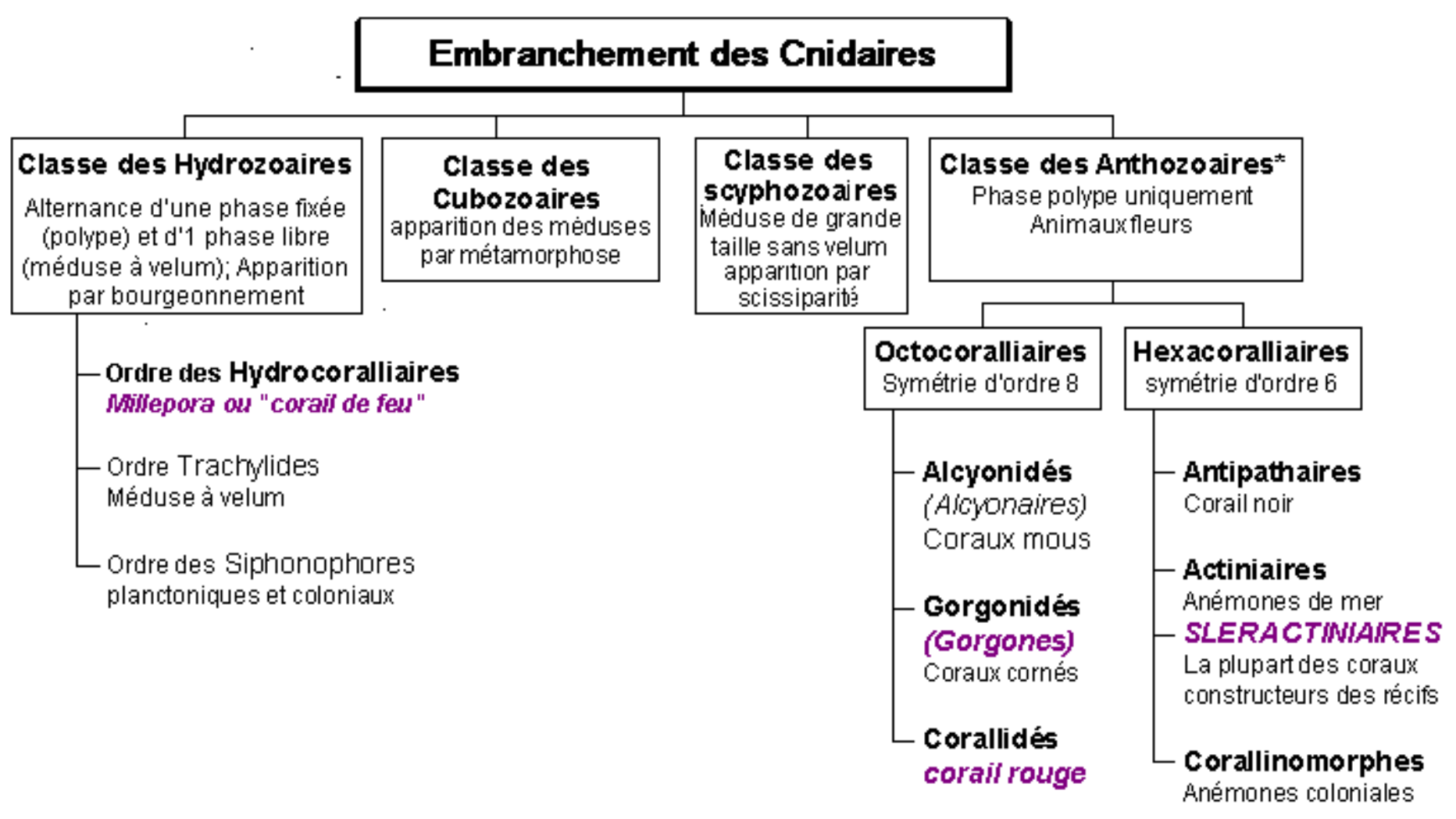

Figure 8 : classification des Cnidaires. Tiré de (16). 
Tous les Cnidaires possèdent des organelles appelés nématocystes ou cnidocystes, situés sur des tentacules, qui transpercent la peau et y relarguent du venin en cas de contact. Classiquement, le contact provoque de la douleur, puis un érythème, suivi par une éruption papuleuse, prurigineuse, parfois nécrotique, qui persiste 3 à 7 jours. Le vinaigre permet généralement d'antagoniser le venin contenu dans les nématocystes.(17) Les séquelles à long terme incluent la formation de cicatrices chéloïdes, l'hyperpigmentation, ou l'atrophie graisseuse. Il peut y avoir une réaction systémique, avec fièvre, malaise, nausées et vomissements, urticaire, réactions d'hypersensibilité, acidose respiratoire, crampes musculaires, arthralgies et convulsions. Exceptionnellement, la mort peut survenir par arrêt respiratoire, cardiaque, insuffisance hépatique ou rénale, ou anaphylaxie.

Les Cnidaires provoquent des réactions par un mécanisme toxique initial, puis allergique, avec des réactions précoces ou tardives, comme l'anaphylaxie, l'urticaire, des lésions papuleuses ou granulomateuses persistantes.(18)

\section{a/ coraux}

Les coraux appartiennent à l'embranchement des Cnidaires, à la classe des Anthozoa. Ils peuvent provoquer des blessures physiques à cause de leur structure calcaire, dure et tranchante, ou par envenimation par les nématocystes. Cette envenimation peut provoquer une réaction aigue, retardée, et chronique.(19)

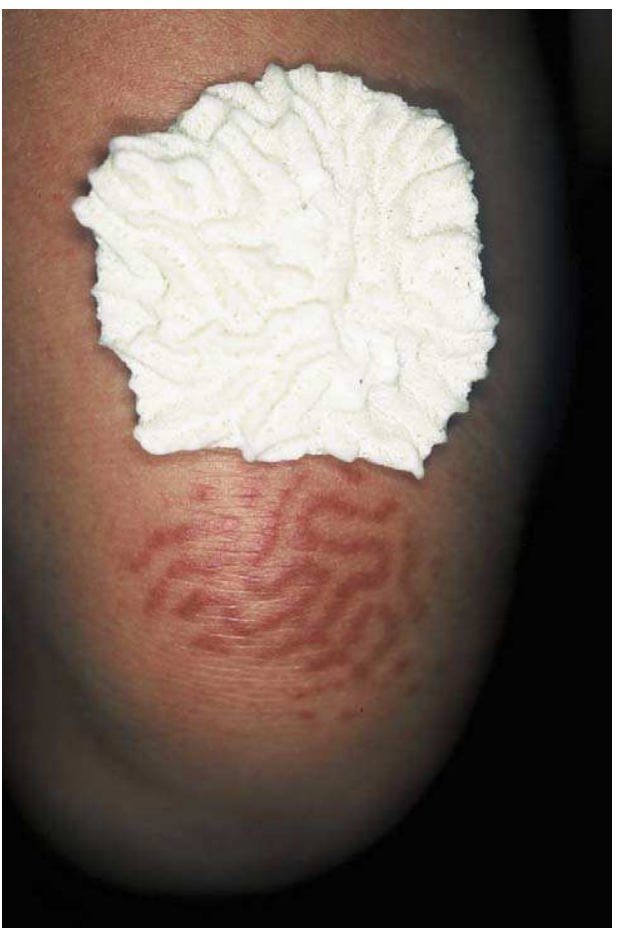

Figure 9 : réaction d'hypersensibilité retardée de contact mimant les marques du corail Diploria. Tiré de Dagregorio, 2006 (20). 
Les réactions aigues se développent quelques minutes à quelques heures après le contact. Il peut s'agir d'urticaire aigue ou de lésions vésiculo-bulleuses. Les réactions retardées apparaissent quelques jours à semaines après le contact, comme nous l'avons constaté dans plusieurs cas de notre étude.

Les réactions chroniques peuvent être des récurrences, ou la persistance d'une dermatose lichénoïde. Il s'agit alors plus d'allergie que de réaction toxique.

Les coraux de feu (Millepora dichotoma, ou Millepora platyphylla, figure 10) appartiennent en fait à la classe des Hydrozoa, comme les physalies. Ils sont présents en mer Rouge, dans la région Indo-Pacifique, et les Caraïbes. Ils provoquent des lésions érythémateuses, urticariennes, avec une brûlure due à l'acide formique contenu dans l'enveloppe externe de ce corail. La réaction aigue peut être urticarienne, eczématiforme, vésiculo-bulleuse, hémorragique, nécrotique, ou ulcérée.(18) Des réactions granulomateuses sub-aiguës ou des dermatoses lichénoïdes chroniques peuvent parfois se déclarer quelques semaines après le contact initial avec les nématocystes, avec une cicatrisation prolongée jusqu'à 15 semaines.(20) En cas de contact, l'application d'eau de mer peut soulager la douleur. La désinfection avec de l'ammonium neutralise l'acide formique.(17)

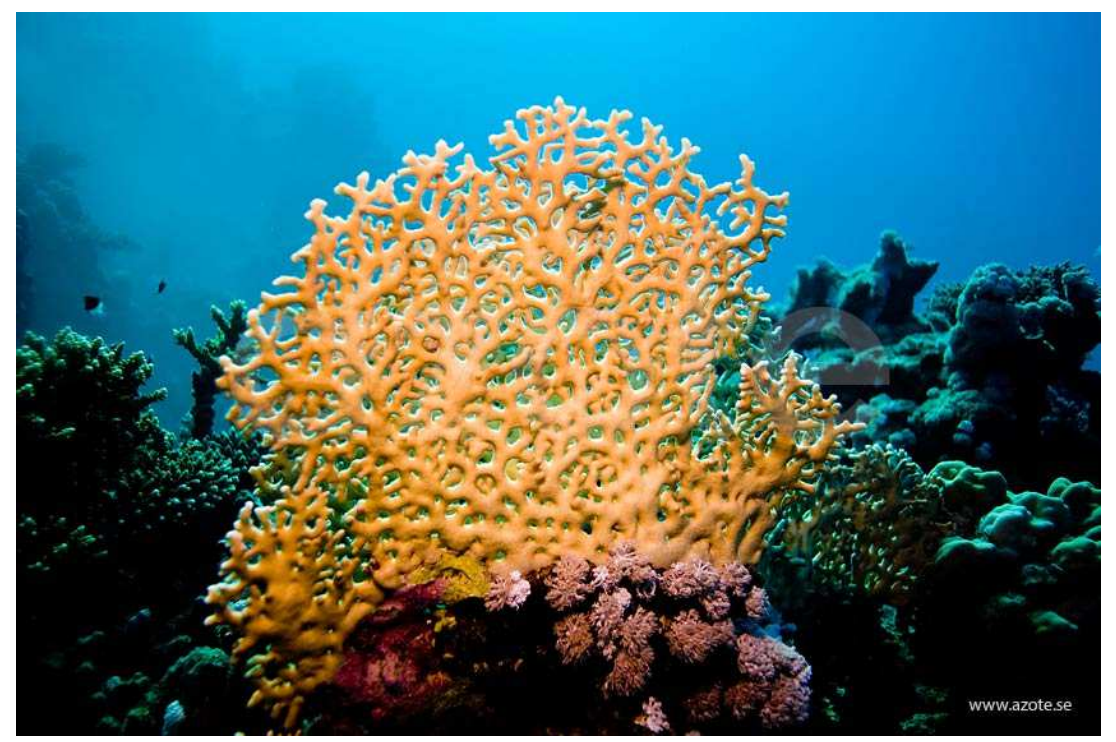

Figure 10 : Millepora dichotoma, ou corail de feu. Egypte. Tiré de (21). 


\section{b/ poisson-pierre}

Le poisson-pierre, ou Synanceia verrucosa (figure 11), appartient à la famille des Scorpaenidae. On le trouve dans toute la région Indo-Pacifique. Il vit principalement à faible profondeur, sur des fonds rocheux, où sa couleur marron, grise, ou rosée, son immobilité, et ses nombreux appendices cutanés sont des atouts majeurs pour se dissimuler. Il peut également s'enterrer dans le sable. Sa peau dépourvue d'écailles sécrète un mucus qui permet l'adhésion du sable et des débris coralliens, rendant son camouflage très efficace. Sa nageoire dorsale est remplacée par des bourrelets charnus qui dissimulent treize épines contenant du poison.(22) Ce venin est profondément injecté dans le corps lorsque quelqu'un marche dessus par inadvertance.(23) Il a un effet hémolytique et de hyaluronidase, qui provoque des effets cardio-vasculaires et neuro-musculaires.(24)

La douleur syncopale lors de l'envenimation peut être à l'origine de noyade. La région piquée prend rapidement un aspect inflammatoire avec cyanose, suivie d'une nécrose aux points d'injection. Les complications sont immédiates et systémiques : malaise, angoisse, sueurs, frissons, vertiges, parfois collapsus cardio-vasculaire ou détresse respiratoire par atteinte musculaire,(25) pouvant conduire au décès.(26)(27) Il peut y avoir également des complications tardives locales, avec une cellulite nécrosante concentrique, nécessitant une chirurgie.

Le traitement immédiat consiste en une immersion dans l'eau chaude. Des antalgiques de palier 3 sont souvent nécessaires. Une anesthésie locale sans adrénaline ou une anesthésie en bloc loco-régional sont utiles. Il existe un sérum anti-venin, qui doit être administré en cas de douleur trop intense ou de signes généraux.(28)(29) Il nécessite une injection intramusculaire précoce, dans les 15 minutes après l'envenimation, d'une ampoule de 2000UI pour 1 à 2 piqûres, 2 ampoules pour 3 à 4 piqûres, 3 ampoules s'il y a plus de 4 piqûres. Une prémédication par $0.25 \mathrm{mg}$ d'adrénaline sous-cutanée et $100 \mathrm{mg}$ d'hydrocortisone intraveineux est recommandée si possible. Une corticothérapie orale sera associée les 5 jours suivants.(26)

Une étude singapourienne a étudié une série de 8 cas d'envenimation par poissonpierre au niveau de la main (patients hospitalisés en service de chirurgie de la main) et a proposé le protocole de prise en charge suivant : 


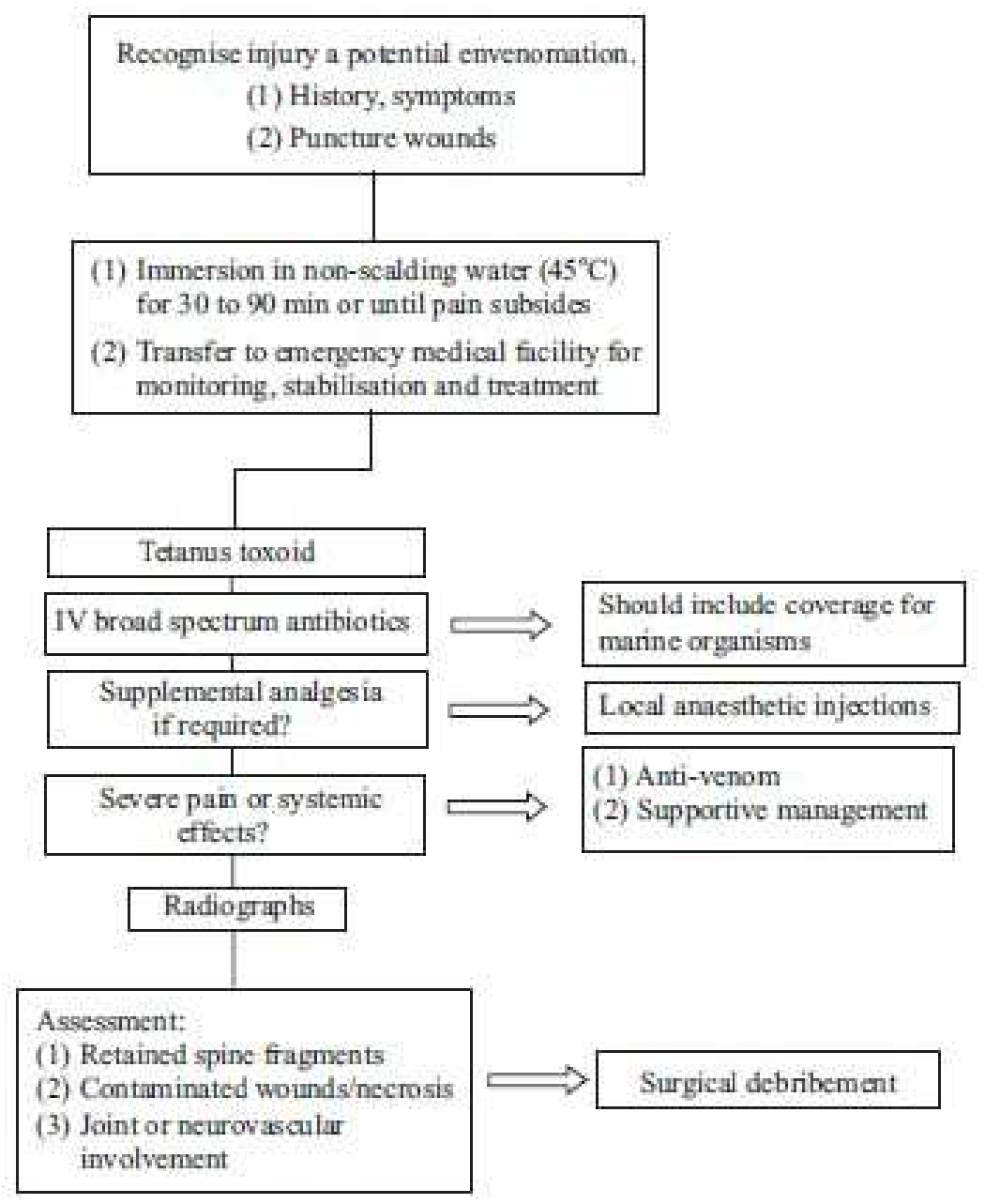

Tableau 7 : algorithme de prise en charge en cas d'envenimation par poisson-pierre. Tiré de (30).

Une autre étude singapourienne étudie 30 cas d'envenimation marine vus aux urgences. Aucun n'a reçu le sérum anti-venin... Cinq cas ont dû être hospitalisés pour l'analgésie ou le traitement des complications locales. Un seul patient a été opéré. Huit patients ont été adressés à un spécialiste, sans qu'il n'y ait eu de retour. (31)

Une seule étude française étudie les complications à long terme de 6 cas d'envenimations par poissons-pierre, chez des voyageurs de retour de la région IndoPacifique. Un patient avait un abcès nécrotique, 2 un ulcère du pied, et 3 une dermohypodermite. Quatre patients ont été opérés, et 2 ont gardé des séquelles sur le long terme.(32) 


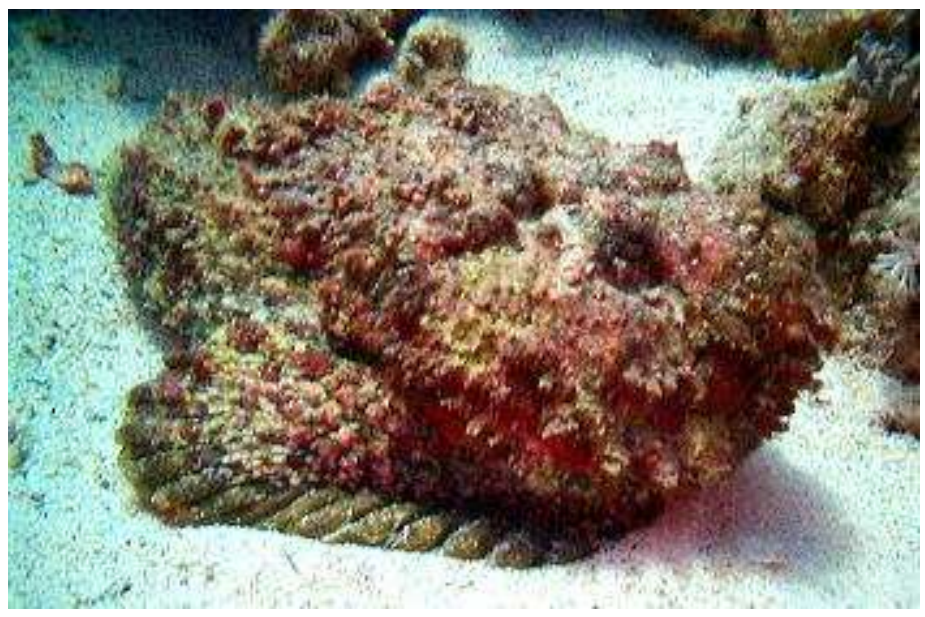

Figure 11 : Synanceai verrucosa. Tiré de (33).

\section{c/ méduses}

Elles appartiennent à l'embranchement des Cnidaires, à la classe des Scyphozoa. Elles se propulsent volontairement grâce aux mouvements de leur ombrelle.

\section{i- $\quad$ Scyphoméduses}

Les «vraies » méduses sont les Scyphozoaires, qui appartiennent à la classe des Scyphozoa. On les trouve dans le monde entier. Leurs tentacules sont répartis tout autour de leur ombrelle. On peut citer en particulier la méduse Aurelia aurita (figure12), cosmopolite. Elles provoquent généralement une dermite irritative, urticarienne, sans conséquence systémique ni prolongée. Toutefois, Nemopilema nomurai est une méduse géante qui a provoqué des décès en Chine.(34)

Le traitement consiste en premier lieu en l'enlèvement des tentacules s'ils sont encore présents sur la peau avec de l'eau de mer. On appliquera ensuite des glaçons enroulés dans un tissu pendant 5 à 15 minutes pour soulager la douleur.(35) 


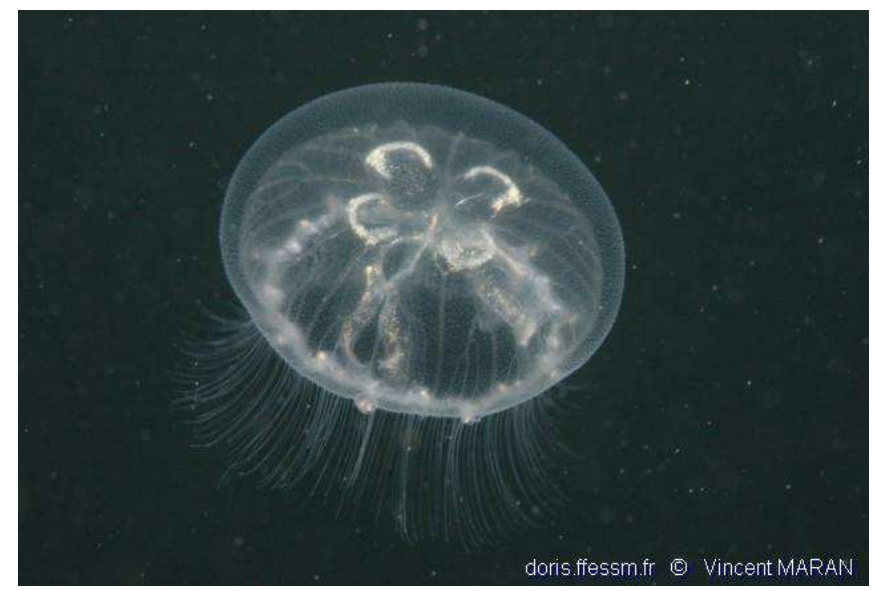

Figure 12 : Aurelia aurita. Tiré de (22).

\section{ii- Cuboméduses}

Elles appartiennent à la classe des Cubozoa. Leur corolle est en forme de boite, ou de cube, avec des tentacules partant des 4 coins de la corolle uniquement. Elles sont séparées en 2 familles :

1-Les Carybdeidae, dont font partie les Carukia barnesi (ou méduses Irukandji), avec un seul tentacule à chaque angle de l'ombrelle. Elles se trouvent dans les eaux du littoral australien, et leur ombrelle ne mesure qu'entre 12 et $30 \mathrm{~mm}$. Les tentacules peuvent mesurer entre $5 \mathrm{~cm}$ et $1 \mathrm{~m}$. La piqûre est presque indolore, mais elle provoque environ 30 minutes plus tard des signes systémiques majeurs, connus sous le nom de syndrome Irukandji : crampes généralisées, myalgies intenses, douleurs thoraciques, sueurs, anxiété, agitation, céphalées, vomissements, polypnée, tremblements, pâleur, hypertension artérielle majeure. Cela peut conduire à un OAP, et une insuffisance cardiaque aigue par dysfonction du ventricule gauche.

Le traitement nécessite des antalgiques de palier 3, de la trinitrine, et des mesures de réanimation.(35)

2-Les Chirodropidae (figure 13), avec une quinzaine de tentacules à chaque angle de l'ombrelle. Elles sont présentes dans les eaux du littoral australien et du Sud-Est Asiatique. Leur ombrelle mesure entre 25 et $30 \mathrm{~cm}$ de diamètre, et les tentacules jusqu'à $3 \mathrm{~m}$. Elles sont transparentes, et donc difficiles à voir. Elles vont dans les eaux peu profondes lorsqu'il fait 
chaud et que la mer est calme. Leur toxine contient des éléments hémolytiques, neurotoxiques, et cardiotoxiques.

La douleur est intolérable. La peau est brûlée, avec des bulles puis une nécrose cutanée, avec persistance de cicatrices à vie. L'arrêt respiratoire peut survenir en quelques minutes sans soins, avec un OAP par effet cardiotoxique.

Le traitement est l'application immédiate de vinaigre, (36) associée aux mesures de réanimation cardio-pulmonaire. Après l'application de vinaigre, on fera un pansement compressif des zones de piqûre les plus grandes. La glace peut aider à soulager la douleur. Du sérum anti-venin existe contre Chironex. Il doit être utilisé en cas d'envenimation importante : 3 ampoules de 20000 unités par voie intra-musculaire ou intra-veineuse immédiatement, et encore 3 en service de réanimation.(35)

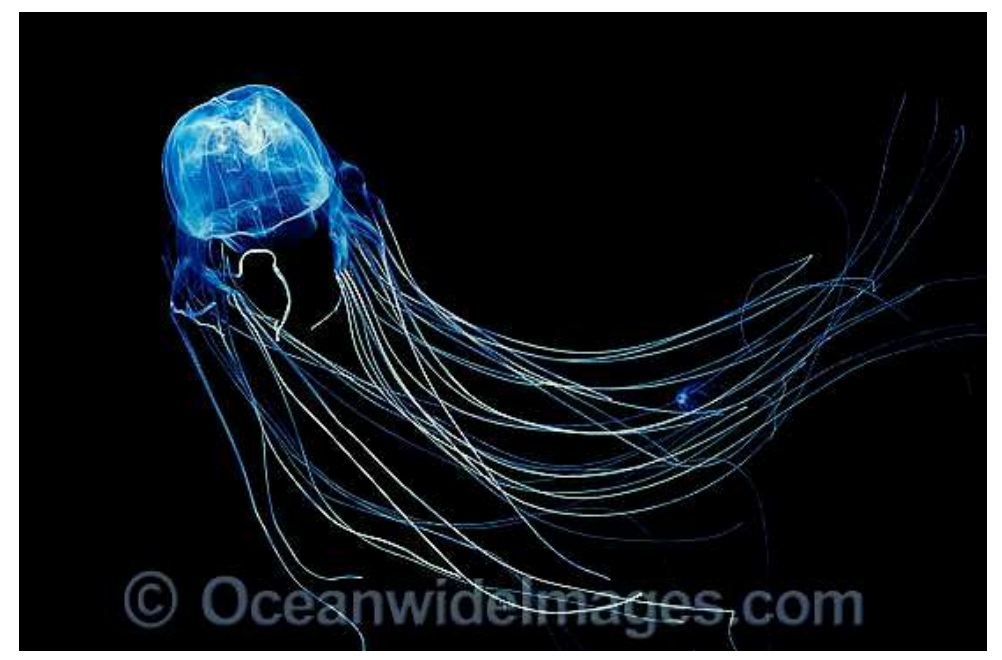

Figure 13. Chironex fleckeri. Tiré de (37).

Les méduses en général s'étendent actuellement partout dans le monde. Les causes évoquées sont la surpêche, le réchauffement climatique, les modifications des habitats, l'aquaculture, les changements de salinité, l'acidification des océans, et la translocation de méduses.(38) 


\section{d/ physalia physalis}

Contrairement aux apparences, les Physalia (figure 14) ne sont pas des méduses, mais sont souvent prises pour des méduses par les novices. Elles appartiennent à l'embranchement des Cnidaires, à la classe des Hydrozoa, à l'ordre des Siphonophorae, et sont composées de plusieurs colonies de polypes.(39) Les physalies se rencontrent habituellement dans les mers chaudes, dans le Pacifique (Physalia utriculus), mais également dans l'Atlantique (Physalia physalis) avec ces dernières années des épidémies importantes en Bretagne (40) et sur la côte Atlantique en France.(41)

Elles flottent à la surface de l'eau grâce à leur flotteur rempli d'air, et ne peuvent se diriger volontairement. Leur couleur bleue leur a valu le surnom de «bluebottle», ou «portuguese man-of-war » en anglais. Les tentacules mesurent en moyenne une dizaine de mètres, mais peuvent aller jusqu'à 50m de long. Ils sont composés de cellules spécialisées, les cnidoblastes, qui contiennent les nématocystes, et s'encrent dans la peau en cas de contact. Les physalies peuvent s'échouer sur la plage, et restent venimeuses.

Le contact avec une physalie engendre une douleur intense, une sensation de brûlure, d'anxiété, et des signes généraux avec nausées, faiblesse et bradycardie. Localement, elle engendre de longues plaques d'urticaire, érythémateuse, prurigineuse, qui dure de 3 à 7 jours. La zone touchée peut devenir violacée, vésiculeuse ou nécrotique. Il peut parfois y avoir une réaction systémique, avec des vertiges, des nausées, une sensation de faiblesse et exceptionnellement un décès.(18)

Une récente étude brésilienne de 331 cas d'envenimations par des physalies en 3 jours, retrouve des signes systémiques chez moins de $10 \%$ des patients. $12.9 \%$ des patients ont eu la persistance de signes tardifs après la piqûre initiale (hyperpigmentation cutanée, prurit chronique).(42)

Le traitement est l'eau chaude, idéalement entre 42 et $45^{\circ} \mathrm{C}$, pendant 30 à 90 minutes, qui permet de soulager la douleur. Le vinaigre ne doit pas être utilisé car il fait se décharger les nématocystes.(43) Cependant, au Brésil a été utilisé de la glace pour soulager les douleurs, ainsi que du vinaigre.(42) Son intérêt est donc controversé dans cette utilisation. 


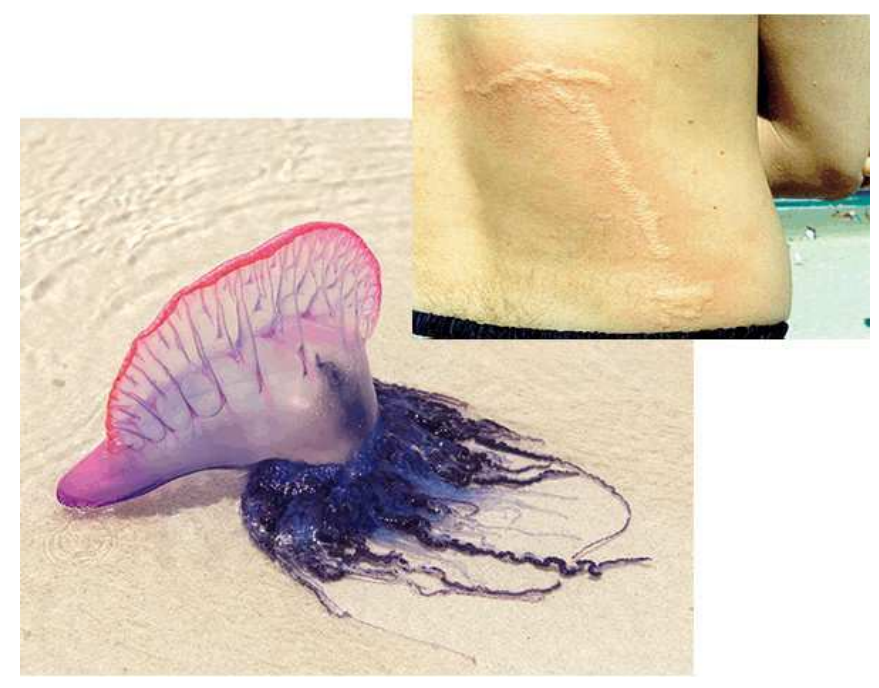

Figure 14 : Physalia physalis et l'aspect d'une piqûre. Tiré de (45).

\section{e/ raies}

Appartenant à la classe des Chondrichthyes, les espèces venimeuses de raies se répartissent en 7 familles, rencontrées dans les mers tropicales, la Méditerranée, et l'océan Atlantique (figure 15). Elles possèdent un appendice caudal pourvu d'un ou deux aiguillons caducs, d'environ $10 \mathrm{~cm}$, dotés de 2 rangs de denticules rétrogrades et de 2 appareils glandulaires. Les accidents surviennent sur des fonds peu profonds, sablonneux. La projection de la queue pour harponner permet une injection du venin par la pénétration du dard. La profondeur de la plaie varie de 2 à $10 \mathrm{~cm}$ selon la taille de l'aiguillon, avec parfois de grandes lacérations. La douleur immédiate, souvent lancinante sur 48 heures, irradie à tout le membre et s'accompagne de paresthésies. Autour de l'impact apparaissent des signes inflammatoires avec un œdème infiltré et éventuellement des phlyctènes hémorragiques.(26) En l'absence de traitement, la surinfection est constante, avec apparition d'une escarre nécrotique. Dans les cas les plus graves, il peut y avoir des signes généraux et de manière exceptionnelle des décès.(44) On a découvert récemment que le venin de raie possède des propriétés cardiotoxiques.(45)

Le traitement consiste en un nettoyage de la plaie à l'eau de mer, puis en l'immersion dans l'eau chaude, et d'une compression en cas de saignement important. Il est nécessaire d'extraire l'aiguillon et les tissus abimés, avec une exploration chirurgicale, puis de combler la cavité par un pansement à base d'alginate pour absorber les toxines, à garder en place une dizaine de jours.(28) En cas de blessure au niveau du thorax, une imagerie s'impose en urgence. Une antibioprophylaxie par triméthoprime/sulfaméthoxazole est recommandée en cas de plaie profonde, pour son action contre les différentes espèces de Vibrios.(45) 
Dans une étude récente de plus de 400 blessures par raies au Brésil, dont 137 par des raies marines (les autres sont dues à des raies d'eau douce), le symptôme principal était la douleur majeure, avec un œdème local et un érythème. Une nécrose cutanée d'intensité variable était présente dans $75 \%$ des envenimations par raies marines, et $100 \%$ dans les raies d'eau douce. Un ulcère concentrique apparaissait parfois, pouvant durer plus de 3 mois.(46)

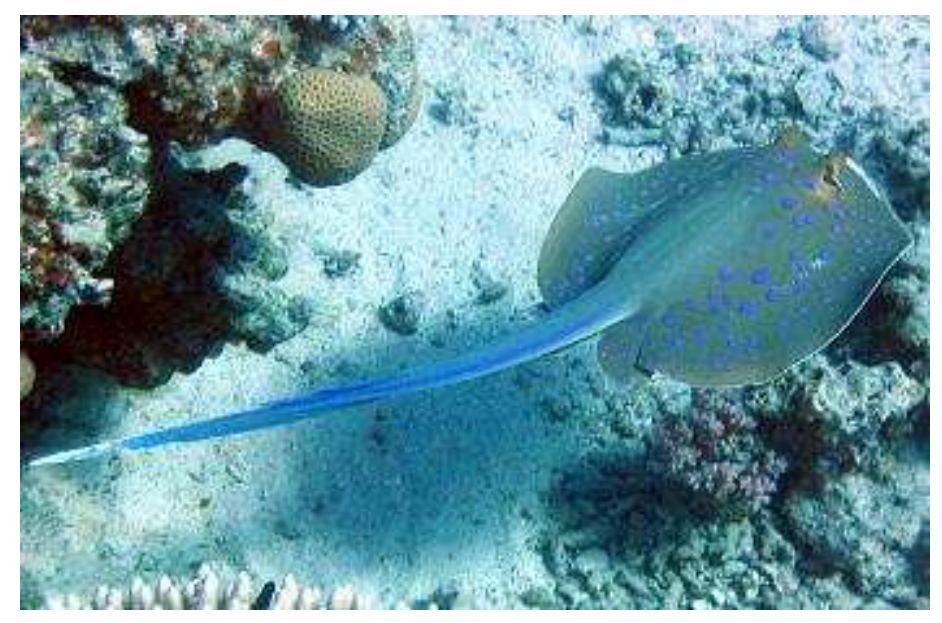

Figure 15 : Taeniura lymma, ou raie pastenague à pois bleus. Tiré de (33).

\section{f/ vive}

La vive, ou Trachinus draco (figure 16), est présente en mer du Nord, dans l'Atlantique du sud de la Norvège au Maroc, en Méditerranée et en mer Noire. Elle vit dans les fonds sableux ou vaseux côtiers, à faible profondeur en été. Elle s'y enfouit en ne laissant dépasser que ses yeux et ses rayons venimeux de la nageoire dorsale.(22) Le venin thermolabile, hémolytique et neurotoxique agit sur le système cardio-vasculaire. Il contiendrait de l'histamine, adrénaline et noradrénaline. La douleur instantanée est syncopale, avec localement un œdème et une cyanose du membre, pouvant évoluer vers une nécrose circonscrite. Des lipothymies ou vertiges, une tachycardie et une dyspnée sont fréquentes. Des convulsions et états délirants sont parfois décrits, le décès par défaillance cardiaque est exceptionnel.(26)

Le traitement consiste en un lavage à l'eau de mer, puis à un bain dans de l'eau très chaude.

Les études reprenant de manière descriptive les cas d'envenimations par vives sont très rares. Une étude israélienne rapporte le cas de 79 envenimations marines chez des 
pêcheurs, dont 17 envenimations par vives. Mais les caractéristiques de chaque type d'envenimation ne sont pas détaillées.(47)

Une deuxième étude israélienne plus descriptive rapporte 3 cas d'envenimations par vive. Au stade aigu, la douleur est très intense, ayant nécessité un traitement par opiacés et par l'eau chaude. Le suivi n'a été possible que pour un patient, chez qui un odème a persisté, comme ce fut le cas chez nos deux patients.(48)

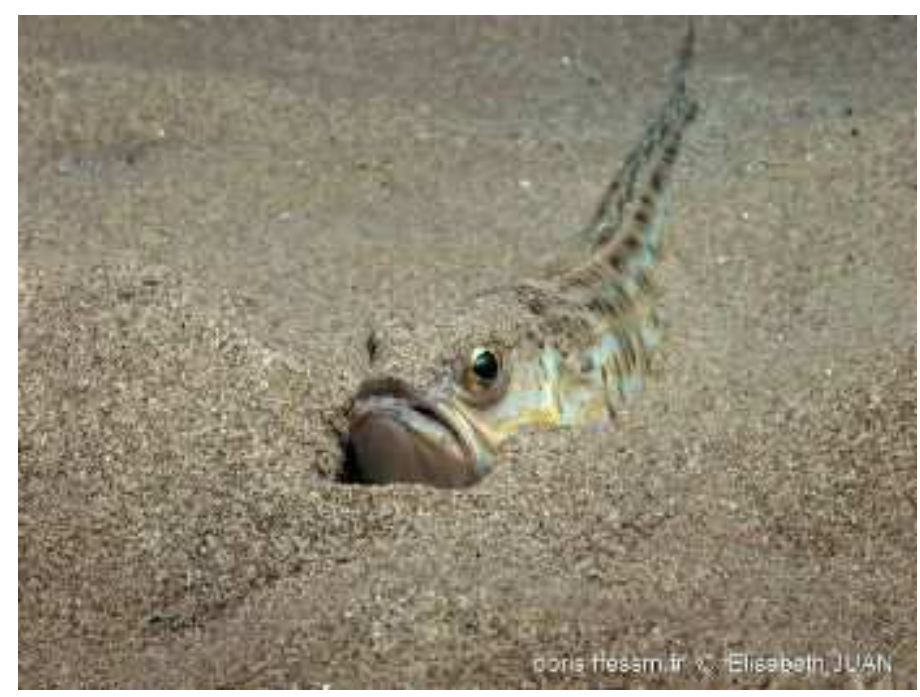

Figure 16 : Trachinus draco, ou grande vive. Tiré de (22).

\section{g/ étoiles de mer}

Les piqûres des étoiles de mer, ou Astérides (classe des échinodermes, figure 17), sont sans gravité et n'entrainent qu'un érythème prurigineux bénin. Seule l'Acanthaster planci est potentiellement dangereuse.(26) Elle est présente dans tout l'océan Indien et Pacifique. L'acanthaster se dissimule le jour et se nourrit de corail la nuit. On assiste à une recrudescence de cette étoile car son seul prédateur, le triton, est un joli coquillage chassé à outrance pour sa coquille, menaçant ainsi les récifs coralliens. Le dos et les 9 à 23 bras sont recouverts d'épines acérées et venimeuses.(22) L'envenimation se traduit par une douleur cuisante et des signes locaux inflammatoires et hémorragiques, puis parfois des paresthésies du membre et une lymphangite.

Le traitement consiste en une immersion dans l'eau chaude, le venin étant thermolabile, et l'extraction des épines.(26) 


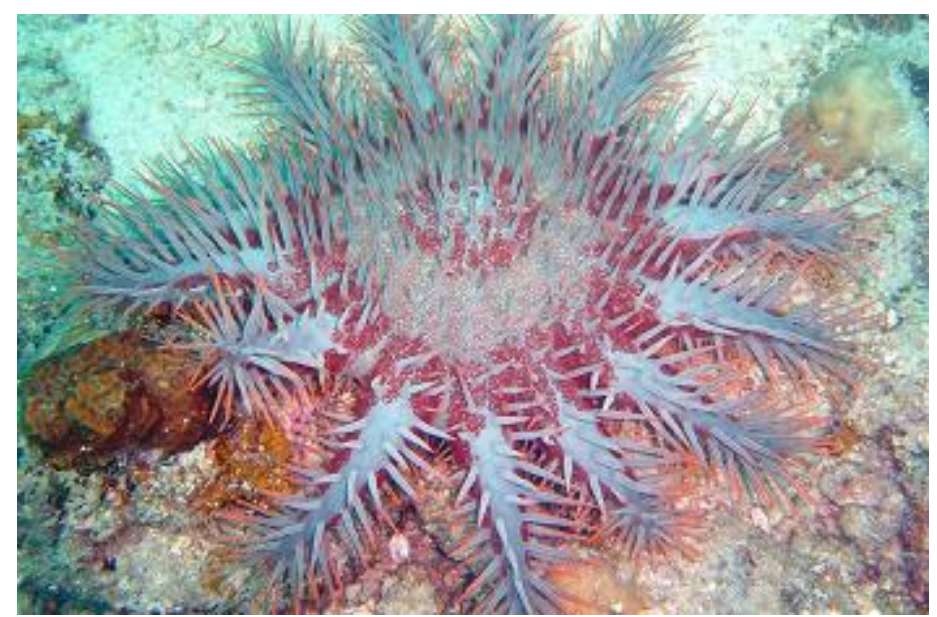

Figure 17 : Acanthaster planci. Tiré de (33).

\section{h/ anémone de mer}

Elles appartiennent à l'embranchement des Cnidaires, dans la classe Anthozoa. Les anémones de mer dangereuses sont principalement Actinodendron plumosum (figure 19) et Triactis producta (figure 20). Le contact provoque une sensation de piqûre, suivie par un œdème, un érythème, des hémorragies pétéchiales, et des ecchymoses. Rapidement, une dermite irritative figurée apparait avec une éruption prurigineuse, érythémateuse, vésiculopapuleuse. Les signes systémiques sont classiques (syndrome vagal, crampes, choc anaphylactique). L'éruption disparait généralement en une à deux semaines, mais une nécrose ou une ulcération peuvent se former.(17) Les cicatrices dyschromiques sont classiques.(26)

L'étude de centaines de cas de personnes vivant à Long Island dans l'État de New York, ramasseurs de coquillages, qui ont développé une dermatose prurigineuse, érythémateuse, vésiculo-papuleuse aux zones de contact a permis de découvrir la pathogénicité de Haloclava producta, une anémone de mer qui s'enfouit dans le sable.(49)

Les anémones de mer sont aussi responsable de la «dermite du baigneur de mer » ou Seabather's eruption (figure 18), lésions prurigineuses érythémateuses, maculeuses, papuleuses, ou urticariennes, limitées aux zones couvertes par le maillot de bain, et accentuées au niveau des plis. Elle est due aux larves de l'anémone de mer Edwardsiella linate (50) ou aux larves de Linuche unguiculata, la méduse en dé à coudre.(51) 


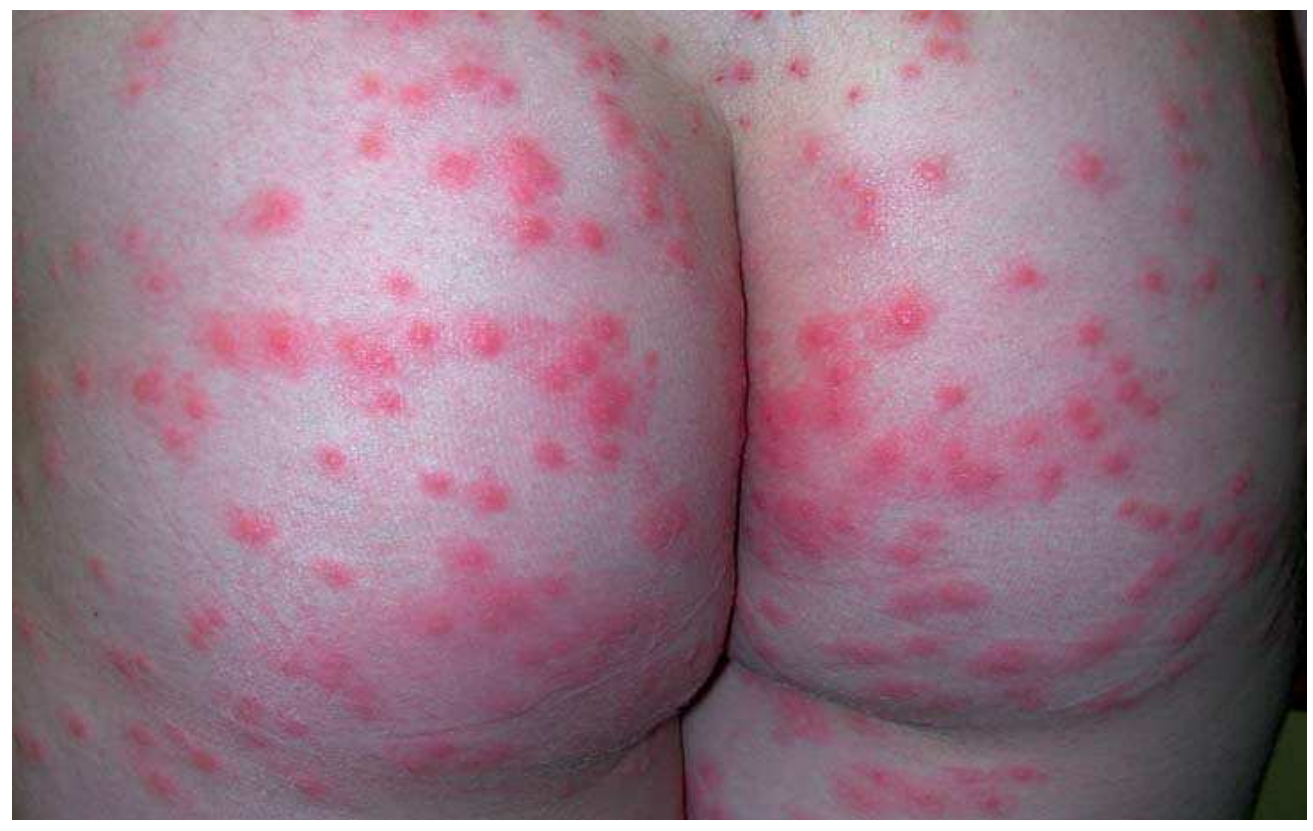

Figure 18: "éruption du baigneur de mer". Tiré de (51).

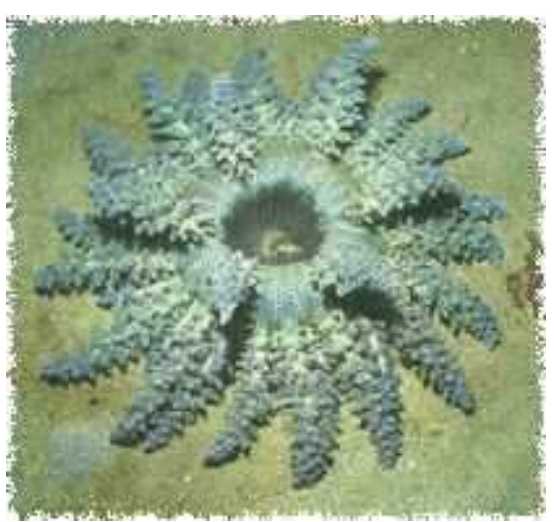

Figure 19 : Actinodendron plumosu.

Tiré de (52).

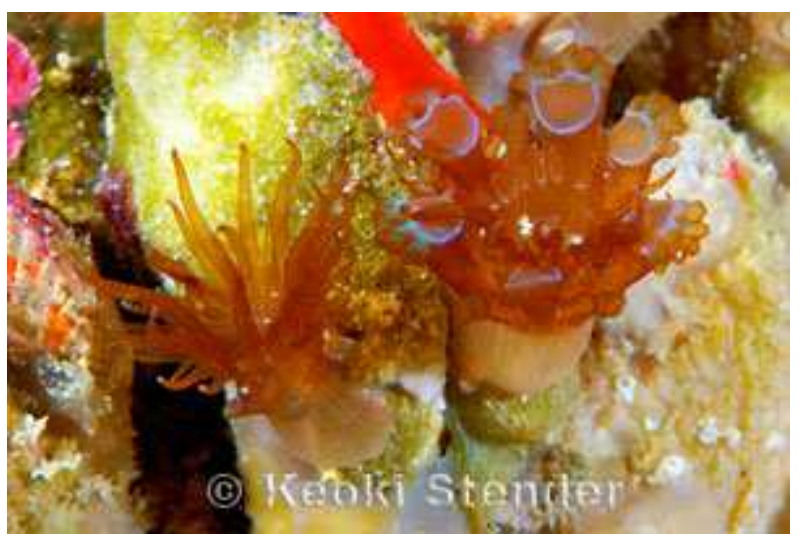

Figure 20 : Triactis producta, Hawaii Tiré de (53).

\section{i/ poissons lions}

Appelés également rascasses, ils sont présents dans le Pacifique, de la Malaisie à la Polynésie française et du Sud du Japon à l'Océanie (Pterois volitans), et en mer Rouge et dans tout l'océan Indien (Pterois miles, figure 21). Les deux espèces ont été introduites dans les Caraïbes.(22) Ils sont responsables de blessures surtout chez les plongeurs. Leurs épines 
dorsales en forme de drapeaux sont constituées d'épines courtes et épaisses. La douleur est souvent extrêmement intense, irradiante au membre, contrastant avec une blessure souvent punctiforme et hémorragique. Les signes systémiques sont rares.(26)

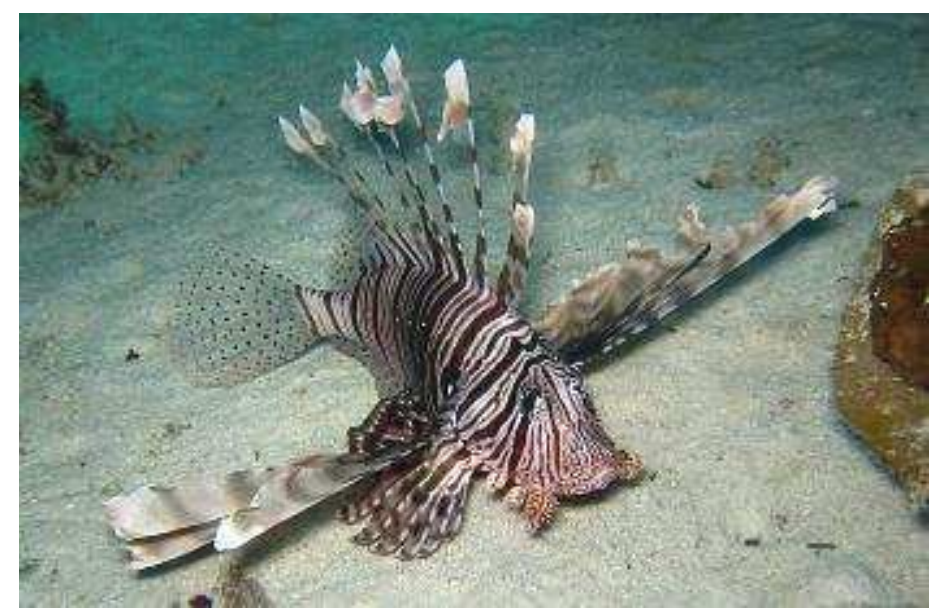

Figure 21 : Pterois miles. Tiré de (33).

\section{2- Complications bactériennes des envenimations marines}

Dans notre étude, une antibiothérapie a été prescrite chez 10 patients sur 37 lors de la consultation post-voyage. Cela montre bien la fréquence des surinfections bactériennes lors des envenimations marines. Certaines espèces bactériennes particulières peuvent surinfecter des plaies à l'origine minimes. Elles sont donc importantes à connaitre :

-Erysipelothrix rhusiopathiae est un bacille Gram positif que l'on peut trouver dans le porc ou les poissons. Il provoque des érysipèloïdes, ou rouget du porc, après une inoculation par blessure. Il s'agit d'une plaque érythémateuse souvent prurigineuse, parfois douloureuse, bien limitée, avec peu ou pas de signes généraux. Une dissémination hématogène est possible, causant alors un sepsis, des arthrites septiques ou des endocardites. Le germe est sensible à la pénicilline G.(18)

-Vibrio vulnificus est un bacille à Gram négatif présent dans les eaux douces et marines. Il peut infecter des plaies et causer des infections nécrosantes type cellulite ou fasciite. Il colonise également des animaux marins ou coquillages, notamment les huitres en saison chaude, et en cas d'ingestion par une personne immunodéprimée, diabétique ou cirrhotique, provoquer un sepsis sévère avec fasciite nécrosante de dissémination hématogène, 
de mauvais pronostic. Le traitement outre les soins intensifs et la chirurgie consiste en l'injection intraveineuse de cyclines associées à des C3G, ou de la ciprofloxacine.(54)

-Aeromonas hydrophyla est un bacille à Gram négatif retrouvé dans les eaux douces et saumâtres, tropicales ou non. Ils peuvent surinfecter des plaies et causer des cellulites très inflammatoires voire bulleuses et nécrotiques. Le traitement repose sur les fluoroquinolones ; la chirurgie est souvent nécessaire.(54)

-Mycobacterium marinum est une mycobactérie atypique qui infecte la peau lésée des extrémités des personnes en contact avec l'eau de mer ou douce, y compris les aquariums. Les lésions cutanées apparaissent quelques semaines à mois après l'inoculation, à type de papule ou nodule sur le site de l'inoculation. La lésion grandit formant une nécrose et une ulcération, avec une dissémination sporotrichoïde. Elle peut provoquer une ténosynovite, ou une arthrite septique. Le traitement repose sur une association d'antibiotiques, parmi la clarithromycine et l'éthambutol, voire la rifampicine, la minocycline, le trimétoprime-sulfaméthoxazole, ou la ciprofloxacine. L'utilisation de compresses chaudes sur les lésions ou la chirurgie peuvent être associées.(18)

-Chromobacterium violaceum est un bacille Gram négatif aérobie, saprophyte des sols et des eaux en région tropicale. Il pénètre la peau lésée, et provoque une ulcération inflammatoire avec un écoulement purulent bleuté. Une bactériémie peut survenir notamment chez l'immunodéprimé, causant un sepsis avec apparition de lésions maculeuses disséminées qui s'ulcèrent. Il peut également y avoir des abcès osseux ou hépatiques. Chromobacterium violaceum est sensible aux fluoroquinolones, aminosides, imipénème, trimétoprimesulfaméthoxazole.(55)

-Les Shewanella sont des bactéries à Gram négatif, saprophyte de l'eau des régions tempérées et tropicales. Elles provoquent des ulcérations profondes avec des bulles hémorragiques sur les membres inférieurs généralement, pouvant se compliquer de fasciite nécrosante et d'ostéomyélite. Elles peuvent également causer des otites et des bactériémies, voire des endocardites et méningites. Elles sont sensibles aux C3G, aux fluoroquinolones et aux aminosides.(55) 


\section{3- Points forts et limites de notre étude}

Les points forts de notre étude consistent en son originalité : plusieurs études décrivent les envenimations marines en phase aigüe, mais très peu à distance. Ainsi notre étude permet de décrire les conséquences à moyen et parfois à long terme de diverses envenimations marines. Les patients piqués par poisson-pierre ont même bénéficié de consultations de suivi ultérieures pour 7 patients sur 10 .

Les proportions de chaque cause d'envenimation vu en consultation post-voyage ne reflète pas forcément la fréquence de ce type d'envenimation, mais la fréquence de ces complications, ayant nécessité une consultation spécialisée à distance. Notre étude est donc particulièrement novatrice dans ce domaine.

Notre étude est une étude rétrospective, monocentrique, sur un effectif relativement limité de patients pour chaque type d'envenimation. Il peut exister un biais de mémoire car les patients sont vus à distance de l'envenimation, et peuvent ne pas se souvenir de l'aspect ou des traitements initiaux. Ceci explique certaines données manquantes pour quelques patients.

Elle concerne des personnes vivant en France, et qui voyagent dans des lieux privilégiés par les Français pour des raisons culturelles ou historiques. Elles ne sont donc pas forcément représentatives des envenimations possiblement rencontrées dans le monde entier.

La cause de l'envenimation ne peut être à chaque fois formellement établie. Elle est souvent présumée par les données géographiques, l'aspect cutané et les symptômes de l'envenimation. La cause, surtout lorsqu'il s'agit d'une méduse ou d'un poisson, peut ne pas avoir été vue, et il s'agit alors d'un diagnostic présomptif. 


\section{Conclusion :}

Les envenimations marines sont un problème croissant dans le monde, compte tenu de la multiplication des activités aquatiques. Les envenimations marines potentiellement mortelles en particulier risquent de devenir plus fréquentes, compte tenu de l'extension des zones de présence des méduses-boites. Les patients survivant aux piqûres de ces méduses gardent des séquelles esthétiques et psychologiques importantes. Les autres méduses sont moins dangereuses, mais pas beaucoup plus agréables.

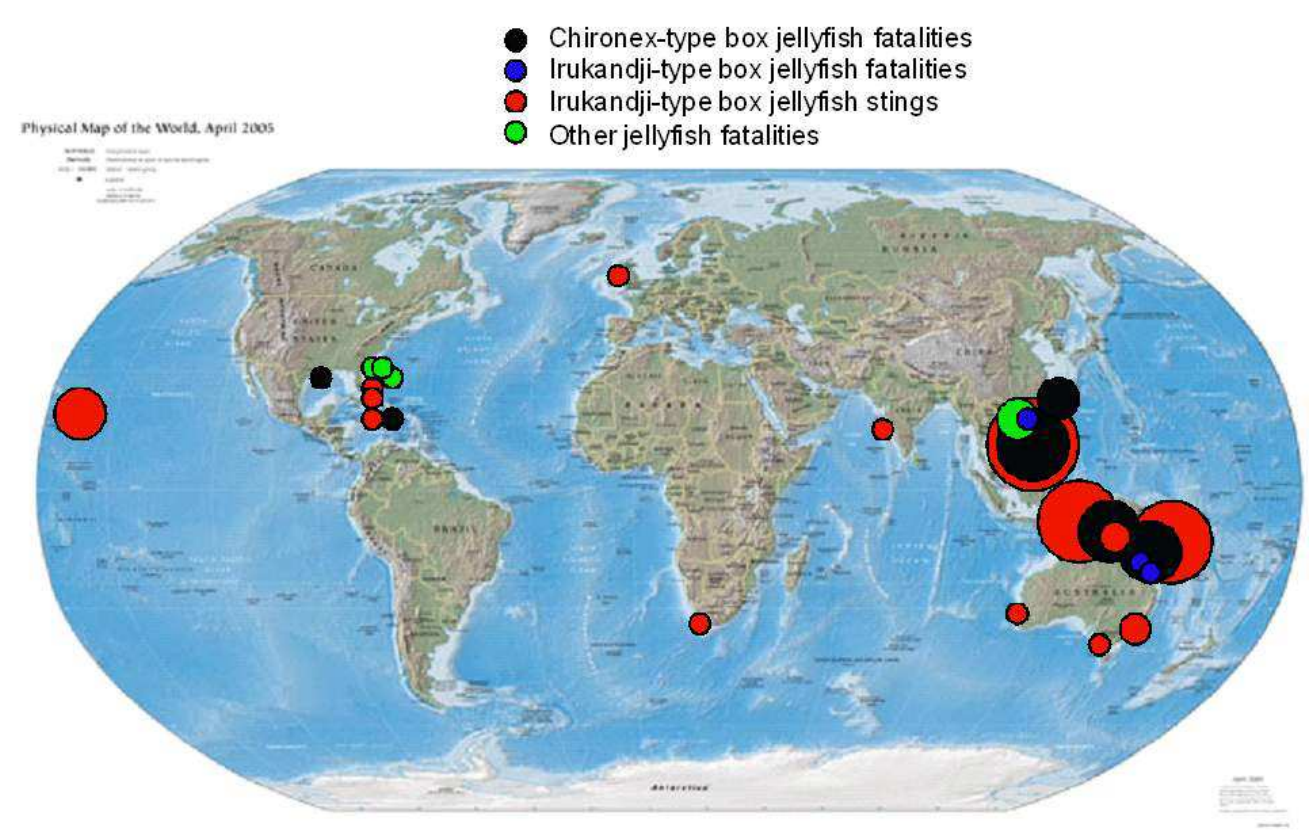

Figure 22 : distribution mondiale des cas rapportés d'envenimation par cuboméduses. Tiré de (56).

Les blessures par coraux génèrent quant à elles peu de conséquences inquiétantes, mais ont été la cause principale d'envenimations marines rencontrée dans notre étude de consultation post-voyage.

Les piqûres par poisson-pierre sont également fréquentes dans notre série, avec parfois de lourdes conséquences locales, allant parfois jusqu'à la chirurgie. 
Nous avons vu qu'il existe de nombreuses autres causes d'envenimations marines, mais également des bactéries pouvant surinfecter des plaies même minimes en contact avec l'eau.

L'étude du spectre des envenimations marines en retour de voyage a permis de définir les envenimations les plus fréquentes, et de préciser leurs caractéristiques cliniques à distance de l'envenimation.

Il est ainsi intéressant de faire connaitre les différentes envenimations marines au public, ainsi qu'aux médecins et en particulier aux dermatologues susceptibles de voir ces patients localement ou à leur retour. La cause de l'envenimation peut souvent être devinée en connaissant la zone géographique où a eu lieu l'envenimation, l'activité au moment de l'envenimation, y compris le fond rocheux ou sablonneux où était situé l'animal, l'aspect clinique et la présence ou non de signes généraux. La reconnaissance visuelle ou par photo facilite évidemment les choses. Connaitre la cause de l'envenimation permet ainsi de guider son traitement immédiat, et savoir si un suivi est nécessaire. 


\section{Bibliographie :}

1. unwto_annual_report_2013.pdf [Internet]. [cited 2014 Jul 29]. Available from: http://dtxtq4w60xqpw.cloudfront.net/sites/all/files/pdf/unwto_annual_report_2013.pdf

2. Boy dies from box jelly fish sting - theage.com.au [Internet]. [cited 2014 Aug 11]. Available from: http://www.theage.com.au/articles/2003/03/24/1048354505551.html

3. Fenner PJ, Lippmann J, Gershwin L-A. Fatal and Nonfatal Severe Jellyfish Stings in Thai Waters. J Travel Med. 2010 Mar 1;17(2):133-8.

4. Lippmann JM, Fenner PJ, Winkel K, Gershwin L-A. Fatal and Severe Box Jellyfish Stings, Including Irukandji Stings, in Malaysia, 2000-2010. J Travel Med. 2011 Jul $1 ; 18(4): 275-81$.

5. Les cuboméduses tuent une cinquantaine de personnes par an [Internet]. Le Monde.fr. [cited 2014 Aug 26]. Available from:

http://www.lemonde.fr/planete/article/2014/08/26/les-cubomeduses-tuent-unecinquantaine-de-personnes-par-an_4476823_3244.html

6. Behrens RH, Carroll B. Travel Trends and Patterns of Travel-Associated Morbidity. Infect Dis Clin North Am. 2012 Sep;26(3):791-802.

7. Hargarten SW, Baker TD, Guptill K. Overseas fatalities of United States citizen travelers: an analysis of deaths related to international travel. Ann Emerg Med. 1991 Jun;20(6):622-6.

8. Paixao ML, Dewar RD, Cossar JH, Covell RG, Reid D. What do Scots die of when abroad? Scott Med J. 1991 Aug;36(4):114-6.

9. Lunetta P. Injury deaths among Finnish residents travelling abroad. Int J Inj Contr Saf Promot. 2010 Sep;17(3):161-8.

10. MacPherson DW, Gushulak BD, Sandhu J. Death and international travel--the Canadian experience: 1996 to 2004. J Travel Med. 2007 Apr;14(2):77-84.

11. Hargarten SW, Baker SP. Fatalities in the Peace Corps. A retrospective study: 1962 through 1983. JAMA J Am Med Assoc. 1985 Sep 13;254(10):1326-9.

12. Travel Medicine Data Collection: GeoSentinel \& Global TravEpiNet - Chapter 1 - 2014 Yellow Book | Travelers' Health | CDC [Internet]. [cited 2014 Jul 30]. Available from: http://wwwnc.cdc.gov/travel/yellowbook/2014/chapter-1-introduction/travel-medicinedata-collection-geosentinel-and-global-travepinet

13. Harvey K, Esposito DH, Han P, Kozarsky P, Freedman DO, Plier DA, et al. Surveillance for travel-related disease--GeoSentinel Surveillance System, United States, 1997-2011. Morb Mortal Wkly Rep Surveill Summ Wash DC 2002. 2013 Jul 19;62:1-23. 
14. Herbinger K-H, Siess C, Nothdurft HD, von Sonnenburg F, Löscher T. Skin disorders among travellers returning from tropical and non-tropical countries consulting a travel medicine clinic. Trop Med Int Health TM IH. 2011 Nov;16(11):1457-64.

15. Bellaud G, Epelboin L, Henn A, Perignon A, Bricaire F, Caumes E. Envenimation marine par cubo-méduse chez un touriste au Cambodge. Bull Société Pathol Exot. 1-4.

16. Classification des coraux (cnidaires) [Internet]. [cited 2014 Aug 26]. Available from: http://vieoceane.free.fr/paf/ficheb2.html

17. Tlougan BE, Podjasek JO, Adams BB. Aquatic sports dematoses. Part 2 - in the water: saltwater dermatoses. Int J Dermatol. 2010 Sep;49(9):994-1002.

18. Haddad V, Lupi O, Lonza JP, Tyring SK. Tropical dermatology: marine and aquatic dermatology. J Am Acad Dermatol. 2009 Nov;61(5):733-750; quiz 751-752.

19. Ahn HS, Yoon SY, Park HJ, Lee JY, Cho BK. A Patient with Delayed Contact Dermatitis to Coral and She Displayed Superficial Granuloma. Ann Dermatol. 2009;21(1):95.

20. Addy JH. Red sea coral contact dermatitis. Int J Dermatol. 1991 Apr;30(4):271-3.

21. Eldkorall (Millepora dichotoma) [Internet]. Azote -den grönaste bildbyrån. [cited 2014 Aug 13]. Available from:

http://www.azote.se/2/index.asp?t=Eldkorall\&q=Eldkorall\&id=9925\&p=1

22. DORIS - FFESSM - Biologie et plongée - Faune et flore sous-marines et dulcicoles [Internet]. [cited 2014 Aug 5]. Available from:

http://doris.ffessm.fr/fiche3.asp?temp=0\&nomcommunte=\&nomcommunpr=\&nomcomm unen $=\&$ allcheck $=\&$ checkvar $=\&$ touslesmotste $=\&$ touslesmotsen $=\&$ touslesmotspr $=\&$ nomc ommun $=\&$ touslesmots $=$ Synanceia $\% 20 \&$ PageCourante $=1 \&$ varpositionf $=1 \&$ fiche_numero $=564 \&$ origine $=$ recherche $\&$ fiche_etat $=4$

23. Comment extraire le venin du poisson le plus venimeux au monde ? [Internet]. [cited 2014 Aug 5]. Available from: http://www.maxisciences.com/poisson-pierre/comment-extrairele-venin-du-poisson-le-plus-venimeux-au-monde_art32939.html

24. Gwee MC, Gopalakrishnakone P, Yuen R, Khoo HE, Low KS. A review of stonefish venoms and toxins. Pharmacol Ther. 1994;64(3):509-28.

25. Lehmann DF, Hardy JC. Stonefish Envenomation. N Engl J Med. 1993;329(7):510-1.

26. Berger L, Caumes E. [Dermatitis and skin injuries from aquatic animals and flora]. Ann Dermatol Vénéréologie. 2004 Apr;131(4):397-404.

27. Maillaud C, Sebat C, Pouradier F, Paladini L, Peres O, Durand F. [Acute circulatory failure following a stonefish envenomation in New Caledonia: case report]. Médecine Trop Rev Corps Santé Colon. 2009 Dec;69(6):591-4.

28. Fenner PJ. Dangers in the Ocean: The Traveler and Marine Envenomation. II. Marine Vertebrates. J Travel Med. 1998 Dec 1;5(4):213-6. 
29. Marine envenomation: An update - A presentation on the current status of marine envenomation first aid and medical treatments.

30. Lee, JYL, Teoh, LC, Leo, SPM. Stonefish envenomations of the hand--a local marine hazard: a series of 8 cases and review of the literature. Ann Acad Med Singapore. 2004;33:515-20.

31. Ngo SY, Ong SH, Ponampalam R. Stonefish envenomation presenting to a Singapore hospital. Singapore Med J. 2009;50(5):506-9.

32. Louis-Francois C, Mathoulin C, Halbwachs C, Grivois JP, Bricaire F, Caumes E. [Skin complications of stonefish envenomation in 6 travellers returning from the Indo-Pacific maritime region]. Bull Société Pathol Exot 1990. 2003 Jan;96(5):415-9.

33. Cours de biologie sous-marine [Internet]. [cited 2014 Aug 14]. Available from: $\mathrm{http} / / /$ puteauxplongee.com/bio/danger.htm

34. Dong Z, Liu D, Keesing JK. Jellyfish blooms in China: Dominant species, causes and consequences. Mar Pollut Bull. 2010 Jul;60(7):954-63.

35. Fenner PJ. Dangers in the Ocean: The Traveler and Marine Envenomation. I. Jellyfish. J Travel Med. 1998 Sep 1;5(3):135-41.

36. Hartwick R, Callanan V, Williamson J. Disarming the box-jellyfish: nematocyst inhibition in Chironex fleckeri. Med J Aust. 1980 Jan 12;1(1):15-20.

37. Box Jellyfish Chironex fleckeri Photo 24M1211-13 [Internet]. [cited 2014 Aug 15]. Available from: http://www.oceanwideimages.com/Large-

Image.asp?pID=2474\&cID=73\&rp=search\%252Easp\%253Fs\%253DChironex\%2Bflecke ri\%2526p\%253D1

38. Brotz L, Cheung WWL, Kleisner K, Pakhomov E, Pauly D. Increasing jellyfish populations: trends in Large Marine Ecosystems. Hydrobiologia. 2012 Jul;690(1):3-20.

39. Lamarck JB. Systême des animaux sans vertèbres; ou, Tableau génral des classes, des classes, des orres et des genres de ces animaux. [Internet]. Paris,: L'Auteur,; 1801 [cited 2014 Jul 30]. Available from:

http://www.marinespecies.org/aphia.php?p=taxdetails\&id=135479

40. Alerte aux physalies, ces organismes sont dangereux [Internet]. Ouest-France.fr. [cited 2014 Aug 13]. Available from: http://www.ouest-france.fr/alerte-aux-physalies-cesorganismes-sont-dangereux-1107058

41. Labadie M, Aldabe B, Ong N, Joncquiert-Latarjet A, Groult V, Poulard A, et al. Portuguese man-of-war (Physalia physalis) envenomation on the Aquitaine Coast of France: an emerging health risk. Clin Toxicol Phila Pa. 2012 Aug;50(7):567-70.

42. Haddad Junior V, Virga R, Bechara A, Silveira FL da, Morandini AC, Haddad Junior V, et al. An outbreak of Portuguese man-of-war (Physalia physalis - Linnaeus, 1758) envenoming in Southeastern Brazil. Rev Soc Bras Med Trop. 2013 Oct;46(5):641-4. 
43. Handbook of Non Drug Intervention (HANDI) Project Team. Hot water immersion for bluebottle stings. Aust Fam Physician. 2013 Jun;42(6):401-2.

44. Fenner PJ, Williamson JA, Skinner RA. Fatal and non-fatal stingray envenomation. Med J Aust. 1989 Dec 4;151(11-12):621-5.

45. Diaz JH. The evaluation, management, and prevention of stingray injuries in travelers. $\mathrm{J}$ Travel Med. 2008 Apr;15(2):102-9.

46. Junior VH, Cardoso JLC, Neto DG. Injuries by marine and freshwater stingrays: history, clinical aspects of the envenomations and current status of a neglected problem in Brazil. J Venom Anim Toxins Trop Dis. 2013 Jul 29;19(1):16.

47. Gweta S, Spanier E, Bentur Y. Venomous fish injuries along the Israeli Mediterranean coast: scope and characterization. Isr Med Assoc J IMAJ. 2008 Nov;10(11):783-8.

48. Halpern P, Sorkine P, Raskin Y. Envenomation by Trachinus draco in the eastern Mediterranean. Eur J Emerg Med Off J Eur Soc Emerg Med. 2002 Sep;9(3):274-7.

49. Freudenthal AR, Barbagallo JS. Ghost anemone dermatitis. J Am Acad Dermatol. 2002 Nov;47(5):722-6.

50. Elston DM. Aquatic antagonists: sea anemone dermatitis. Cutis. 2006;78(1):31-2.

51. Khachemoune A, Yalamanchili R, Rodriguez C. What is your diagnosis? Diagnosis: Seabather's eruption. Cutis. 2006 Mar;77(3):148, 151-2.

52. Dangerous Creatures of the Sea [Internet]. [cited 2014 Aug 13]. Available from: http://web.utah.edu/umed/students/clubs/international/presentations/dangers.html

53. Prolific Anemone, Triactis producta [Internet]. [cited 2014 Aug 13]. Available from: http://www.marinelifephotography.com/marine/cnidaria/triactis-producta.htm

54. Collège des Universitaires de Mladies Infectieuses et Tropicales. e-Pilly TROP maladies infectieuses tropicales. Alinéa Plus. 2012.

55. Diaz JH. Skin and Soft Tissue Infections Following Marine Injuries and Exposures in Travelers. J Travel Med. 2014 May 1;21(3):207-13.

56. World Distribution [Internet]. [cited 2014 Aug 31]. Available from: http://www.stingeradvisor.com/distribution.htm 


\section{$\underline{\text { Annexe } 1 \text { : message d'information du gouvernement du Northern Territory (Australie) }}$}

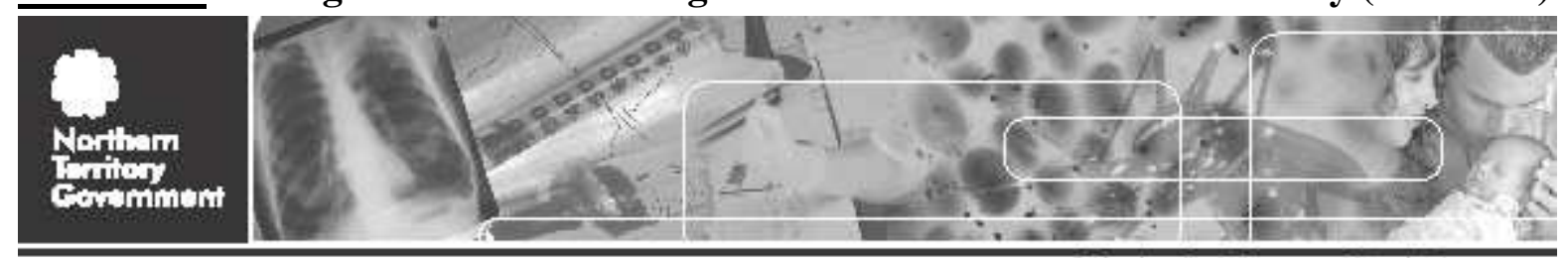

Centre for Disease Control

Chironex fleckeri

November 2012

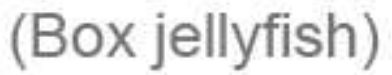

DO NOT ENTER THE SEA AND MOST IMPORTANTLY DO NOT LET CHILDREN ENTER THE SEA DURING THE STINGER SEASON - OCTOBER TO MAY

'Chironex flecken?, also known as the major Box Jellyfish has the most rapidly acting venom known to science and is capable of killing a person in under 5 minutes.

\section{Season}

The official 'stinger' season for the Northern Territory is from 1 October until 1 June. However stings have been recorded in all months of the year.

\section{Distribution}

Chironex fleckeri inhabit the shallow waters of the northern Australian coast, and are more numerous after local rain and in calm seas, especially near river and creek outlets and around boat ramps.

\section{Appearance}

The bell of Chironex flecker is a rounded box shape with the bottom missing, with four fleshy appendages, one at each corner, from which tentacles trail.

The jellyfish is difficult to see in the water because the bell is colourless, and although the outermost tentacles are sometimes purple near their base the others are white or dull yellow.

An adult jellyfish may have 40 or more tentacles, each of which may be up to 2 metres or more in length long. Visible baby Box Jellyfish have bodies $2-5 \mathrm{~cm}$ in diameter, while the larger mature specimens can often be $20 \mathrm{~cm}$ across or even larger.

\section{Envenomation}

The tentacles contain millions of 'nematocysts' which store and can inject venom. A sting occurs when the tentacles contact the bare skin causing these nematocysts to inject millions of little doses of venom into a large area of tissue, which allows very rapid absorption. The venom is fired into the skin within 3 milliseconds of being triggered -10 times faster than the inflation of an airbag in a car crash.

\section{Signs and symptoms}

The venom has cardiotoxic (attacks the heart) and highly dermatonecrotic (destroys skin) components.

A sting causes immediate severe localized pain. Within minutes white welts appear where the tentacie contact occurred, followed by red whip-like lines which may later blister. Subsequent skin death may lead to permanent scarring.

In up to $60 \%$ of cases an itchy bumpy rash can occur days later at the initial site. This 'delayed reaction' can be intensely itchy. The rash usually resolves within 10 days although it may occasionally persist for weeks. Symptomatic relief can be gained by antihistamine use and topical steroids used if the skin is not broken.

A massive dose of venom can cause cardiac dysfunction, resulting in loss of consciousness and cardiac arrest and death within 5 minutes of being stung.

Children are at greater risk of severe, life threatening envenomation because of their smaller body mass.

\section{Injury and deaths}

Around 40 people present to Top End hospitals or health clinics each stinger season with an injury attributed to a jellyfish sting. 


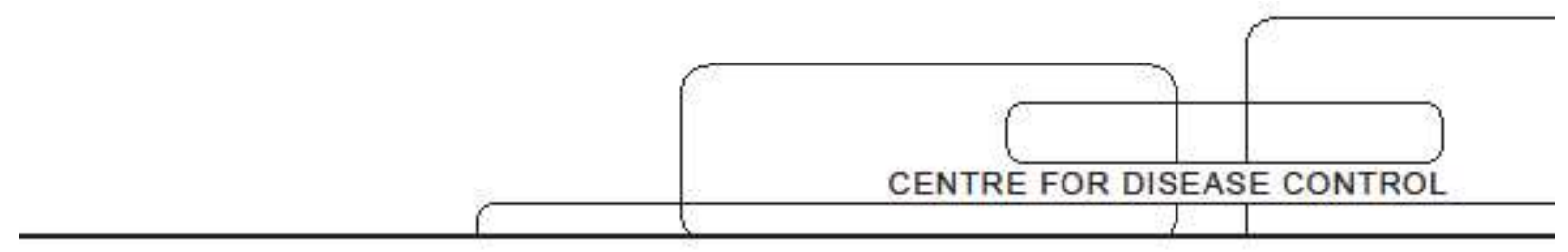

Chironex fleckeri has been responsible for at least 64 deaths since first reported in 1883. The last recorded Chironex fleckeri death in Australia was in a 6 year old boy from a remote NT Aboriginal community in November 2007.

The last 14 stinger deaths in the NT have all been children.

\section{Prevention}

The best prevention is to stay out of the water especially during the stinger season.

If entering the water wear protective clothing. Any clothing, even if very thin, will provide protection as long as there are no gaps or exposed skin. The more skin that is covered, the greater the protection.

\section{Treatment}

Immediate first aid is vital and cardiopulmonary resuscitation may be needed.
- Remove the patient from the water and restrain if necessary

- Call for help (dial 000 or get a surf life saver or life guard to help you)

- Assess the patient and commence CPR as necessary

- Liberally douse the stung area with vinegar to neutralize invisible stinging organelles - do not wash with fresh water

- If vinegar is unavailable, pick off any remnants of the tentacles (the skin of the pads of the fingers and palm is thicker so any stinging will usually be minor) and rinse sting well with salt water (not freshwater)

- Seek urgent medical assistance with rapid transport to hospital. Antivenom may be required in severe stings.

$\begin{aligned} & \text { For more information contact the Centre } \\ & \text { for Disease Control in your region }\end{aligned}$
$\begin{array}{ll}\text { Alice Springs } & 89517540 \\ \text { Darwin } & 89228044 \\ \text { Katherine } & 89739049 \\ \text { Nhulunbury } & 89870357 \\ \text { Tennant Creek } & 89624603 \\ \text { or } & \\ \text { www.nt.gov.au/health/cdc }\end{array}$


Envenimations marines vues en consultation post-voyage à la Pitié Salpêtrière entre 2008 et 2013

Introduction : De nos jours, les voyages et les activités marines se multiplient, et donc le risque d'envenimation marine. L'objectif de ce travail est d'étudier les caractéristiques des envenimations marines chez des personnes de retour de voyage.

Matériel et méthodes : A partir de la base de données GeoSentinel, nous avons étudié les dossiers des patients vus en consultation post-voyage pour envenimation marine à la Pitié Salpêtrière entre 2008 à 2013.

Résultats : Un total de 37 patients a été étudié : 11 cas d'envenimation marine par coraux, 10 par poisson-pierre, 8 par méduses, 2 par vives, 2 par étoiles de mer, 2 par raies, un par poisson- lion, un par anémone de mer. Les destinations de voyage les plus fréquentes étaient l'Asie du Sud-Est (10 patients) et les îles à l'Est de l'Afrique (7 patients). La durée médiane entre l'envenimation et la consultation était de 14 jours (2 à 130 jours). La durée médiane entre le retour et la date de consultation était de 9 jours ( 0 à 120 jours). Le sex ratio était équilibré avec 18 hommes pour 19 femmes. L'âge médian des patients était de 42 ans (25 à 68 ans). La durée médiane de séjour était de 14 jours (6 à 62 jours). Le but du voyage était le tourisme dans $100 \%$ des cas. Les caractéristiques des différentes envenimations sont décrites.

Conclusion : L'étude du spectre des envenimations marines en retour de voyage a permis de définir les envenimations les plus fréquentes, et de préciser leurs caractéristiques cliniques à distance de l'envenimation.

Marine envenomations in returning travellers in a French hospital, 2008-2013.

Introduction: Nowadays, travels and aquatic leisures are increasing, and so is the risk of marine envenomation.

Methods: Cases were defined as returning travellers consulting between 2008 and 2013 at the Pitié Salpêtrière hospital, based on the GeoSentinel database.

Results: 37 patients were studied: 11 cases of marine envenomation by corals, 10 by stonefish, 8 by jellyfish, 2 by weever fish, 2 by starfish, 2 by stingray, one by lionfish, one by sea anemone. The most frequent travel destination was South East Asia in 10 cases, and East of Africa's islands in 7 cases. Median time between envenomation and consultation was 9 days (2 to 130 days). Sex ratio was balanced with 18 men and 19 women. Median age was 42 years (25 to 68). Median stay duration was 14 days (6 to 62 days). Purpose of travel was tourism in all cases. The characteristics of each type of envenomation are described.

Conclusion: Studying the range of marine envenomations in returning travellers has permitted to define the most frequent envenomations and to point out the clinical characteristics some time after the injury.

Mots clés : envenimations marines, voyageurs, retour de voyage, cuboméduse, poissonpierre, coraux, vive, raie.

Key words: marine envenomation, travellers, returning travellers, box jellyfish, stonefish, corals, weever fish, stingray.

Faculté de médecine Paris Descartes - 15 rue de l'école de médecine 75006 Paris 